\title{
Significance of Mixed Convection and Arrhenius Activation Energy in a Non-Newtonian Third Grade Fluid Flow Containing Gyrotactic Microorganisms Towards Stretching Surface
}

\section{Abdullah Dawar}

Abdul Wali Khan University Mardan

Saeed Islam

Abdul Wali Khan University Mardan

Zahir Shah ( $\sim$ zahir@ulm.edu.pk)

university of Lakki marwat

Poom Kumam

King Mongkut's University of Technology Thonburi

\section{Research Article}

Keywords: Third grade fluid, mixed convection, Arrhenius activation energy, Gyrotactic Microorganisms, MHD, Stretching surface

Posted Date: January 18th, 2021

DOI: https://doi.org/10.21203/rs.3.rs-146062/v1

License: (c) (i) This work is licensed under a Creative Commons Attribution 4.0 International License.

Read Full License 


\title{
Significance of Mixed Convection and Arrhenius Activation Energy in a Non-Newtonian Third Grade Fluid Flow Containing Gyrotactic Microorganisms towards Stretching Surface
}

\author{
Abdullah Dawar ${ }^{a}$, Saeed Islam ${ }^{a}$, Zahir Shah ${ }^{b, c}$, Poom Kumam ${ }^{c, d}$ \\ ${ }^{a}$ Department of Mathematics, Abdul Wali Khan University, Mardan 23200, Khyber \\ Pakhtunkhwa, Pakistan. \\ ${ }^{b}$ Department of Mathematics, University of Lakki Marwat, Lakki Marwat 28420, Khyber \\ Pakhtunkhwa Pakistan \\ ${ }^{c}$ Center of Excellence in Theoretical and Computational Science (TaCS-CoE), Faculty of \\ Science, King Mongkut's University of Technology Thonburi (KMUTT), 126 Pracha Uthit Rd., \\ Bang Mod, Thung Khru, Bangkok 10140, Thailand \\ ${ }^{d}$ Fixed Point Research Laboratory, Fixed Point Theory and Applications Research Group, \\ Center of Excellence in Theoretical and Computational Science (TaCS-CoE), Faculty of Science, \\ King Mongkut's University of Technology Thonburi (KMUTT), 126 Pracha Uthit Rd., Bang \\ Mod, Thung Khru, Bangkok 10140, Thailand \\ Corresponding authors: Poom Kumam(poom.kum@kmutt.ac.th) and Zahir Shah \\ (zahir@ulm.edu.pk)
}

\begin{abstract}
In most scenarios of concern, the bulk of fluids treated by researchers and engineers, such as air, water, and oils, can be considered as Newtonian. The inference of Newtonian action however is not true in many situations and the much more complicated non-Newtonian reaction should be superimposed. Such situations exist in the chemical manufacturing sector and the plastics processing plants. Here, we present the mixed convective flow of non-Newtonian third grade fluid containing gyrotactic microorganisms through a stretching surface. The flow is considered as unsteady, laminar, and incompressible. Furthermore, the flow is magnetized and electrically conducting with the help of applied magnetic field. Chemical reaction along with Arrhenius activation energy and viscous dissipation influences are taken into attention. The governing PDEs are transformed to ODEs through appropriate similarity transformations. Analytical and numerical solutions of the present analysis are done with the help of incorporated codes in MATHEMATICA 10.0. Convergence of HAM is presented through Figures. Also, the outcomes of the embedded factors on the nanofluid flow are displayed through Figures.
\end{abstract}


Keywords: Third grade fluid; mixed convection; Arrhenius activation energy; Gyrotactic Microorganisms; MHD; Stretching surface

\section{Introduction}

The inclusion of strong nanoparticles in the heat exchangers significantly increases the fluid's thermal conductivity, which now takes scientists and researchers a few days to draw interest. They have the ability to use the energy devices. In terms of construction, they are robust, costeffective, and simple. References [1-5] have originate their application in thermal transfer devices like aviation sectors, atomic reactors, heat exchangers, and a lot of more. Numerous scholars and analysts have concentrated on this issue in recent decades and have provided many productive and motivated scientific papers. In the context of nanofluid flow containing Ti6Al4V and AA7075, the thermal qualities of porous fin caused by radiation and natural convection through rectangular profiled longitudinal fin were addressed by Sowmya et al. [6]. The numerical exploration of an electrically conducting nanofluid containing microorganisms through a porous extending surface was addressed by Waqas et al. [7]. The comparative analysis of five different nanofluids like: $\mathrm{TiO} 2, \mathrm{CuO}, \mathrm{Ag}, \mathrm{AL} 2 \mathrm{O} 3$, and $\mathrm{Cu}$ whereas $\mathrm{H} 2 \mathrm{O}$ as a base fluid, between an two sheets with the influences of Joule heating, viscous dissipation, thermal radiation, and magnetic field was presented by Ahmad et al. [8]. The 3D radiative flow OldroydB nanofluid with convective conditions through a stretching sheet was explored by Gireesha et al. [9]. The global influence of Williamson parameter on MHD Williamson nanofluid flow through a nonlinear extending surface with Arrhenius activation energy was presented by Dawar et al. [10]. The entropy optimization in MHD water based copper and silver nanofluids between two angularly rotating disks which are kept at constant temperature with the heat generation was determined by Shah et al. [11]. The analytical analysis of electrically conducting MHD micropolar nanofluid flow with secondary slips conditions through an extending surface with nonlinear thermal radiation was discussed by Dawar et al. [12]. Furthermore, the related analyses are mentioned in [13-19].

The analysis of non-Newtonian fluid flow is imperative because of the technical perspective in nonlinear fluid and has real-world uses in various industries. To reveal the existence of nonNewtonian fluids, many fluid models have been proposed. Both natural stresses and the shear 
thickening/thinning phenomenon can be modeled by the third-grade fluid model. Since this fluid model have distinct complications, so the flows of third-grade fluid have been analyzed in numerous ways by many scholars. The time dependent flow of a third grade fluid with heat transmission in a channel was numerically determined by Chinyoka and Makinde [20]. The combined effects of thermal transmission and mass transmission on the flow of third grade fluid were taken into account by Hayat et al. [21]. Owing to a stretching sheet subjected to partial slip, the entrained flow and heat transfer in third grade fluid was regarded by Sahoo and Do [22]. Using the homotopy analysis procedure, the analytical solution for unsteady flow of third grade fluid through a rotating surface was observed by Abbasbandy and Hayat [23]. A study was carried out in an area of stagnation point through an extending surface for the properties of melting thermal transmission in the third grade fluid by Hayat et al. [24]. The MHD flow of third grade fluid using porous medium was presented by Shafiq et al. [25]. In the manifestation of magnetic field, the numerical and analytical solutions of the third grade fluid flow in a hollow vessel using porous medium was analyzed by Hatami et al. [26]. They considered gold as nanoparticles which are added to the base third grade fluid. The incompressible third grade fluid flow with mixed convection using porous medium through an extending surface was probed by Hayat et al. [27]. The inquiry of MHD third grade fluid through an inverted cone with radiation impact was presented by Gaffar et al. [28]. The coating process using a simple fixed blade on a moving substrate for a third-grade fluid was discussed by Sajid et al. [29]. The two-dimensional MHD flow of Jeffrey nanofluid containing gyrotactic microorganisms through a stratified stretching sheet was examined by Waqas et al. [30].

In view of the literature survey, we present the bioconvective flow of non-Newtonian third grade fluid containing gyrotactic microorganisms through a stretching surface. The flow is considered as unsteady, laminar, and incompressible. The governing PDEs are transformed to ODEs through appropriate similarity transformations. Sections 2-6 present the mathematical modeling, HAM solution, HAM convergence, results and discussion and conclusion respectively.

\section{Mathematical modeling}

The unsteady and incompressible flow of motile gyrotactic microorganisms suspended in a third grade nanofluid through a stretching surface is considered. The nonlinear mixed convective 
influence is taken into account. Viscous dissipation and activation energy is also considered in the fluid flow. Using these suppositions, the principal equations are defined as:

$$
\begin{gathered}
\frac{\partial u}{\partial x}+\frac{\partial v}{\partial y}=0 \\
\frac{\partial u}{\partial t}+u \frac{\partial u}{\partial x}+v \frac{\partial u}{\partial y}=\frac{\alpha_{1}^{*}}{\rho_{f}}\left(\frac{\partial^{3} u}{\partial t \partial y^{2}}+u \frac{\partial^{3} u}{\partial x \partial y^{2}}+\frac{\partial^{2} u}{\partial y^{2}} \frac{\partial u}{\partial x}+v \frac{\partial^{3} u}{\partial y^{3}}+3 \frac{\partial u}{\partial x} \frac{\partial^{2} u}{\partial x \partial y}\right) \\
+2 \frac{\alpha_{2}^{*}}{\rho_{f}}\left(\frac{\partial^{2} u}{\partial x \partial y} \frac{\partial u}{\partial y}\right)+6 \frac{\alpha_{3}^{*}}{\rho_{f}} \frac{\partial^{2} u}{\partial y^{2}}\left(\frac{\partial u}{\partial y}\right)^{2}-\sigma \frac{B_{0}^{2}}{\rho_{f}} u+ \\
\frac{g}{\rho_{f}}\left[\rho_{f} \beta^{*}\left(T-T_{\infty}\right)\left(1-C_{\infty}\right)-\gamma^{*}\left(\rho_{m}-\rho_{f}\right)\left(N-N_{\infty}\right)-\left(C-C_{\infty}\right)\left(\rho_{p}-\rho_{f}\right)\right] \\
\frac{\partial T}{\partial t}+u \frac{\partial T}{\partial x}+v \frac{\partial T}{\partial y}=\frac{1}{\left(\rho c_{p}\right)_{f}} \frac{\partial}{\partial y}\left[K(T) \frac{\partial T}{\partial y}\right]+\frac{\mu(T)}{\left(\rho c_{p}\right)_{f}}\left(\frac{\partial u}{\partial y}\right)^{2} \\
\frac{\alpha_{1}^{*}}{\left(\rho c_{p}\right)}\left(u \frac{\partial^{2} u}{\partial x \partial y} \frac{\partial u}{\partial y}+v \frac{\partial^{2} u}{\partial y^{2}} \frac{\partial u}{\partial y}\right)+2 \frac{\beta^{*}}{\left(\rho c_{p}\right)}\left(\frac{\partial u}{\partial y}\right)^{2}, \\
\frac{\partial C}{\partial t}+u \frac{\partial C}{\partial x}+v \frac{\partial C}{\partial y}=D \frac{\partial^{2} C}{\partial y^{2}}-k_{0}^{2}\left(C-C_{\infty}\right)\left(\frac{T}{T_{\infty}}\right)^{n} e^{\left[\frac{-E_{a}}{\kappa T}\right]} \\
\frac{\partial N}{\partial t}+u \frac{\partial N}{\partial x}+v \frac{\partial N}{\partial y}=D_{m} \frac{\partial^{2} C}{\partial y^{2}}-\frac{b_{c} W_{c}}{\left(C_{w}-C_{\infty}\right)} \frac{\partial}{\partial y}\left(N \frac{\partial C}{\partial y}\right)
\end{gathered}
$$

with boundary conditions

$$
\begin{aligned}
& u=a x, v=0, T=T_{w}, C=C_{w}, N=N_{w}, \text { at } y=0, \\
& u \rightarrow 0, T \rightarrow 0, C \rightarrow 0, N \rightarrow 0, \text { at } y \rightarrow \infty .
\end{aligned}
$$

The terms $\mu(T)$ and $K(T)$ are defined as:

$$
\mu(T)=\mu_{0}\left(e^{-\alpha \theta}\right)=\mu_{0}(1-\alpha \theta), K(T)=k_{\infty}\left(1+\frac{\varepsilon\left(T-T_{\infty}\right)}{\Delta T}\right),
$$


where $k_{\infty}$ is the ambient fluid conductivity, $\alpha$ is the fluid viscosity parameter, and $\varepsilon$ is the constant of thermal dependent conductivity.

Considering the similarity variables as:

$$
\begin{aligned}
& u=\frac{b x}{(1-a t)} f^{\prime}(\xi), v=-\left(\frac{b v}{(1-a t)}\right)^{\frac{1}{2}} f(\xi), \theta(\xi)=\frac{T-T_{\infty}}{T_{w}-T_{\infty}} \\
& \phi(\xi)=\frac{C-C_{\infty}}{C_{w}-C_{\infty}}, h(\xi)=\frac{N-N_{\infty}}{N_{w}-N_{\infty}}, \xi=\left(\frac{b}{v(1-a t)}\right)^{\frac{1}{2}} y, \psi=\left(\frac{b v}{(1-a t)}\right)^{\frac{1}{2}} x f(\xi) .
\end{aligned}
$$

Using the similarity transformations defined in eq. (8), eqs. (2-6) are reduced as

$$
\begin{aligned}
& (1-\alpha \theta) f^{\prime \prime \prime}-\alpha \theta^{\prime} f^{\prime \prime}-f^{\prime 2}+f f^{\prime \prime}-S\left(f^{\prime}+\frac{\xi}{2} f^{\prime \prime}\right)+\varepsilon_{1}\left(2 f^{\prime \prime \prime} f^{\prime}-f f^{\prime \prime \prime}+S\left(2 f^{\prime \prime \prime}+\frac{\xi}{2} f^{\prime \prime \prime \prime}\right)\right) \\
& +3 \varepsilon_{1} f^{\prime \prime 2}+2 \varepsilon_{2} f^{\prime \prime 2}+6 \varepsilon_{3} f^{\prime \prime 2} f^{\prime \prime \prime}+\lambda\left(\theta-\left(N_{1} \phi+N_{2} h\right)\right)=0 \\
& \frac{1}{\operatorname{Pr}}(1-\varepsilon \theta) \theta^{\prime \prime}+\frac{1}{\operatorname{Pr}} \varepsilon \theta+f \theta^{\prime}-S\left(\theta+\frac{\xi}{2} \theta^{\prime}\right)+ \\
& E c(1-\alpha \theta) f^{\prime \prime 2}+\varepsilon_{1} f f^{\prime \prime 2}-\varepsilon_{1} f f^{\prime \prime} f^{\prime \prime \prime}+2 \varepsilon_{3} \operatorname{Re} f^{\prime \prime 2}=0, \\
& \frac{1}{S c} \theta^{\prime \prime}+f \phi^{\prime}-S\left(\phi+\frac{\xi}{2} \phi^{\prime}\right)-\sigma \phi(1+\delta \theta)^{n} e^{\left.\frac{-E_{1}}{1+\delta \theta}\right]}=0, \\
& h^{\prime \prime}+f h^{\prime}-S\left(h+\frac{\xi}{2} h^{\prime}\right)+L_{b} h^{\prime}-P e\left(\phi^{\prime \prime}(h+\Omega)+\phi^{\prime} h^{\prime}\right)=0, \\
& f(0)=0, f^{\prime}(0)=\theta(0)=\phi(0)=h(0)=1, f^{\prime}(\infty)=\theta(\infty)=\phi(\infty)=h(\infty)=0 .
\end{aligned}
$$

where $S=\frac{a}{b}$ indicates the unsteady parameter, $\varepsilon_{1}=\frac{b \alpha_{1}^{*}}{\mu_{0}}, \varepsilon_{2}=\frac{b \alpha_{2}^{*}}{\mu_{0}}$ are the material parameters, $\varepsilon_{3}=\frac{a^{2} \alpha_{3}^{*}}{\mu_{0}}$ signifies the third grade fluid parameter, $\lambda=\frac{(1-a t)^{2}\left(1-C_{\infty}\right)\left(T_{w}-T_{\infty}\right) g \beta^{*}}{x b^{2}}$ 
represents the mixed convection parameter, $N_{1}=\frac{\left(\rho_{p}-\rho_{f}\right)\left(C_{w}-C_{\infty}\right)}{\beta^{*} \rho_{f}\left(1-C_{\infty}\right)\left(T_{w}-T_{\infty}\right)}$ indicates the buoyancy ratio parameter, $N_{2}=\frac{\left(\rho_{m}-\rho_{f}\right) \gamma^{*}\left(N_{w}-N_{\infty}\right)}{\beta^{*} \rho_{f}\left(1-C_{\infty}\right)\left(T_{w}-T_{\infty}\right)}$ represents the bioconvetion Rayleight number, $\operatorname{Pr}=\frac{\left(\rho c_{p}\right)_{f} v}{k_{\infty}}$ designates the Prandtl number, $E c=\frac{b^{2} x^{2}}{c_{p}\left(T_{w}-T_{\infty}\right)}$ is the Eckert number, Re $=\frac{x^{2} b}{v}$ represents the Reynolds number, $S c=\frac{v}{D_{B}}$ indicates the Schmidt number, $\delta=\frac{\left(T_{w}-T_{\infty}\right)}{T_{w}}$ is the temperature ratio, $\sigma=\frac{k_{r}^{2}}{b}$ signifies the chemical reaction parameter, $L_{b}=\frac{v}{D_{m}}$ is the bioconvection Lewis number, $P e=\frac{b_{c} W_{c}}{D_{m}}$ is the Peclet number, $\Omega=\frac{N_{\infty}}{N_{w}-N_{\infty}}$ is the concentration difference constant of microorganisms, and $E_{1}=\frac{E_{a}}{\kappa T_{\infty}}$ is the activation parameter.

\section{HAM solution}

HAM is used to solve the eqs. (9-12) with boundary conditions (13) with the following conducts. Initial guesses:

$$
f_{0}(\xi)=1-\exp (-\xi), \theta_{0}(\xi)=\exp (-\xi), \phi_{0}(\xi)=\exp (-\xi), h_{0}(\xi)=\exp (-\xi) .
$$

Linear operators

$$
L_{f}(f)=f^{\prime \prime \prime}--^{\prime}, L_{\theta}(\theta)=\theta^{\prime \prime}-\theta, L_{\phi}(\phi)=\phi^{\prime \prime}-\phi, L_{h}(h)=h^{\prime \prime}-h,
$$

with properties:

$$
\begin{aligned}
& L_{f}\left[\mu_{1}+\mu_{2} e^{-\xi}+\mu_{3} e^{\xi}\right]=0, L_{\theta}\left[\mu_{4} e^{-\xi}+\mu_{5} e^{\xi}\right]=0, \\
& L_{\phi}\left[\mu_{6} e^{-\xi}+\mu_{7} e^{\xi}\right]=0, L_{h}\left[\mu_{8} e^{-\xi}+\mu_{9} e^{\xi}\right]=0,
\end{aligned}
$$

where $\mu_{1}, \mu_{2}, \mu_{3}, \ldots, \mu_{9}$ are the arbitrary constants in general solution. 


\section{HAM convergence}

The series solutions of the modeled system of nonlinear equations are treated with HAM. HAM contains an auxiliary parameterh which adjusts and regulates the convergence areas of $f^{\prime}(\xi)$, $\theta(\xi), \phi(\xi)$ and $h(\xi)$. Figure 1(a,b) indicates the convergence regions of $f^{\prime}(\xi), \theta(\xi), \phi(\xi)$ and $h(\xi) \quad$ are $\quad-0.22 \leq \mathrm{h}_{f} \leq 0.02, \quad-0.21 \leq \mathrm{h}_{\theta} \leq 0.0, \quad-0.24 \leq \mathrm{h}_{\phi} \leq 0.01 \quad$ and $\quad-0.4 \leq \mathrm{h}_{h} \leq 0.2$ respectively.

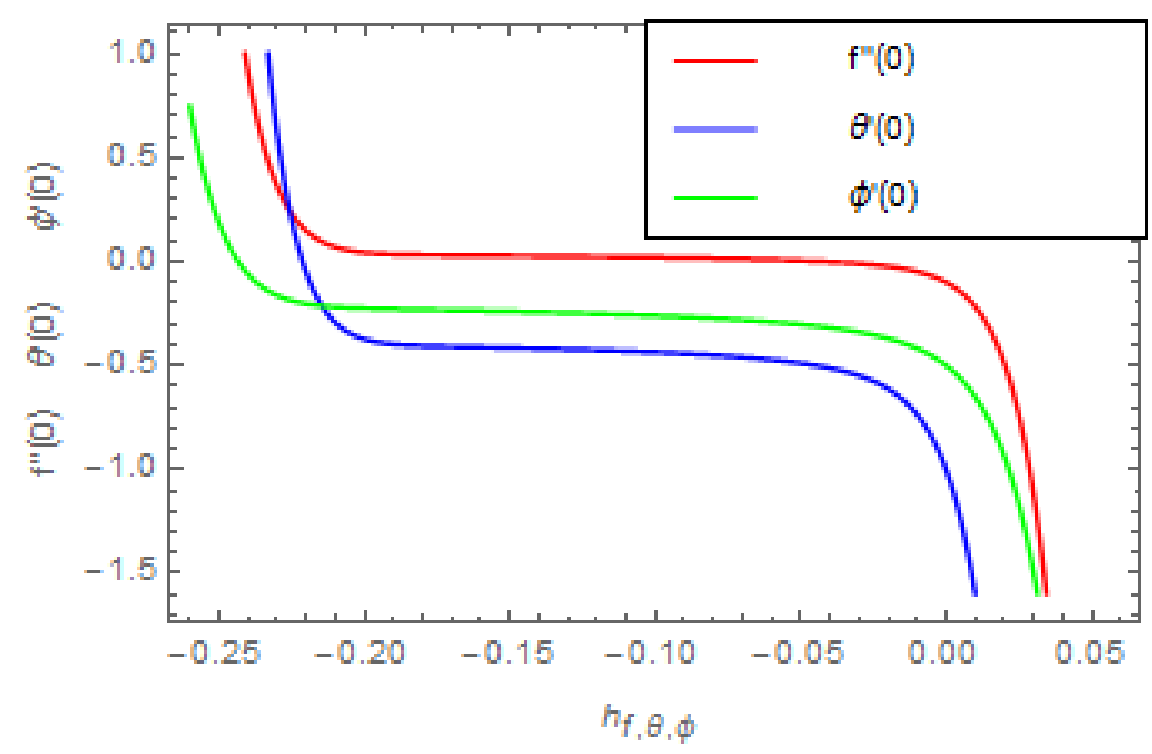

Figure 1(a): $\mathrm{h}$ - curves for $f^{\prime}(\xi), \theta(\xi)$ and $\phi(\xi)$. 


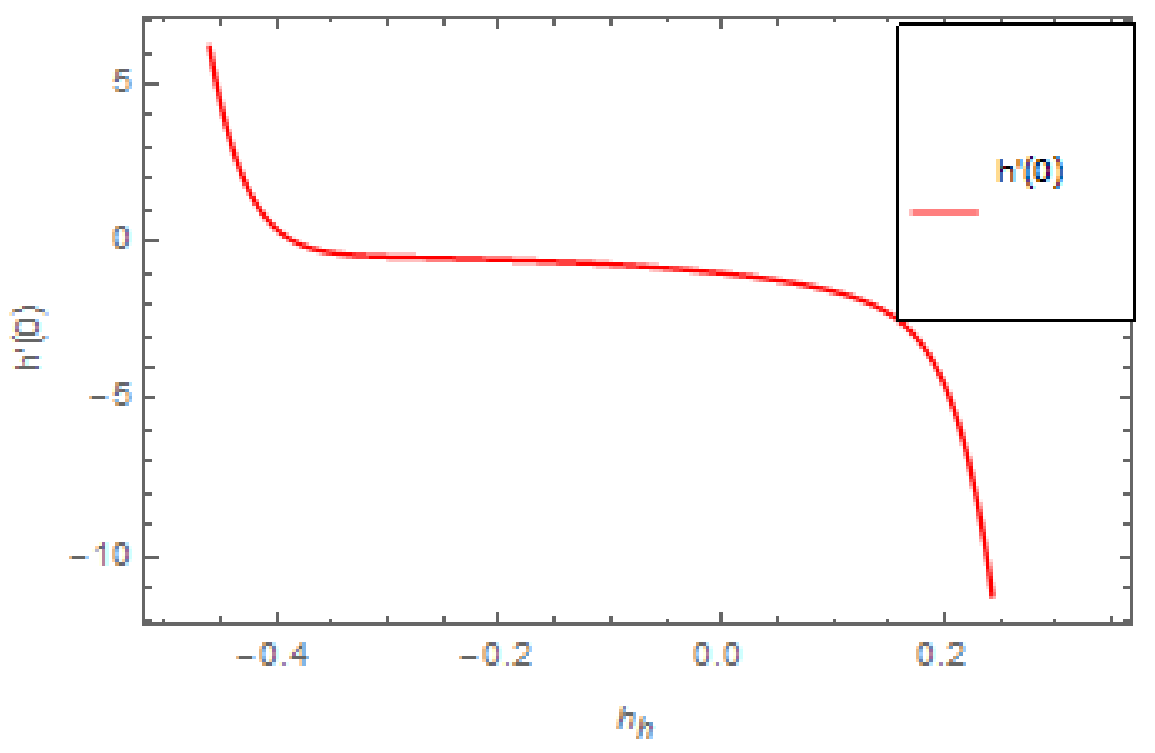

Figure 1(b): $\mathrm{h}$ - curve for $h(\xi)$.

\section{Results and discussion}

An analytical and numerical solution of the present analysis is done with the help of incorporated codes in MATHEMATICA. The unsteady and incompressible flow of motile gyrotactic microorganisms suspended in a third grade nanofluid through a stretching surface is analyzed. The outcomes of the embedded factors on velocity, thermal, concentration, and motile microorganisms motile density functions are presented through Figures 2-7.

Figure 2(a) displays the impact of materials parameters $\left(\varepsilon_{1}, \varepsilon_{2}\right)$ on velocity function. An escalating influence on the velocity function of material parameters is seen here. In point of fact, the heightening material parameters escalate the boundary layer flow and velocity of the nanofluid flow particles, consequently the velocity function escalates.

Figure 2(b) presents the influences of magnetic and viscosity parameters on velocity function. Reducing impacts are depicted here. Actually, the increasing viscosity parameter creates resistive force to the fluid due to which velocity of the fluid flow reduces. Thus, a declining influence is depicted in the velocity function. A similar impact is observed via escalating magnetic parameter. Actually, the magnetic parameter relates with the Lorentz force theory. According to 
Lorentz theory, the heightening magnetic parameter always produces opposing force to fluid flow due to which the fluid velocity declines. Therefore, a declining impression is observed here.

Figure 2(c) portrays the impressions of $\lambda$ and $N_{2}$ on velocity function. An escalating conduct of $\lambda$ on velocity function is observed while a reducing influence is perceived via bioconvective Rayleight number. It is found that the higher values of mixed convection parameter increases the velocity function of the fluid flow. On the other hand, a contrary impact of Rayleight number is depicted. Physically, the increasing estimations of Rayleight number produce the buoyancy force because of bioconvective sources which concludes the reduction in velocity of the fluid flow. Thus, the reducing impact is depicted here.

Figure 2(d) parades the impressions of $\varepsilon_{3}$ and $S$ on the velocity function. Both the parameters have reverse impacts on velocity function. Actually, the heightening $\varepsilon_{3}$ escalates the boundary layer flow and velocity of the nanofluid flow particles due to which the reducing impression in velocity function is observed. Similarly, the increasing estimations of unsteady parameter escalate the stretching rate of sheet due to which the nanofluid flow decelerates. Therefore, the velocity profile is declining function of unsteady parameter.

Figure 3 portrays the impression of Eckert number, conductivity constant parameter, and Prandtl number on thermal function of the nanofluid. A heightening influence of Eckert number on thermal field is depicted here. Greater Eckert number cools down the stretching surface which leads the thermal convection to higher speed. So, the thermal function increases with higher Eckert number. Actually, enhancement in thermal conductivity increases the temperature of the nanofluid particles, consequently the thermal field of the nanofluid flow enhances. Also, Prandtl number has opposite relation with temperature of the flow. The higher values of Prandtl number reduce the temperature of the nanofluid flow. Thus the heightening in Prandtl number reduces the thermal function.

Figure 4 indicates the impressions of activation energy, Schmidt number, and chemical reaction parameter on concentration function. The activation energy parameter increases the concentration function, while a reverse impact is observed via Schmidt number. Substantially, the term $\left(e^{\left(-E_{a} / \kappa T\right)}\right)$ in concentration function plays an important role during this conduction. 
From here, it is determined that the higher values of $E_{1}$ boost the concentration profile. Also, higher values of Schmidt number diminish the concentration function. Physically, the mass diffusivity declines with the escalation in Schmidt number which conclude reduction in concentration function. The higher $\sigma$ reduces the concentration profile. This impact is associated with the theory of activation energy parameter. The increasing $\sigma$ reduces the concentration function. Thus a reducing impact is depicted here also.

Figure 5 presents the influences of bioconvective Lewis number, Peclet number, and concentration difference of microorganisms on microorganisms' motile density function. The higher values of Peclet number heighten the microorganisms' motile density function, while the reverse impact is observed via Lewis number and concentration difference parameter. In point of fact, the increasing values of Peclet number reduce the microorganisms' diffusivity which concludes reduction in microorganisms' motile density function. Also the reducing impacts are depicted via concentration difference of microorganisms and Lewis number.

The direction of imaginary particles suspended in and taken along with the fluid is streamline. The fluid is in motion in a continuous flow, but the streamlines are set. The fluid velocity is comparatively high when streamlines cluster together where they spread up, this fluid is relatively steady. Figure $6(\mathrm{a}-\mathrm{h})$ are displayed to observe the streamlines of the third grade nanofluid flow containing gyrotactic microorganisms. A very interesting behavior is observed on the stretching surface of the sheet for case of the steady and unsteady flow (see Figures (6a) and (6b)). Figures 6(c) and 6(d) display the streamlines for $\varepsilon_{1}=1.0$ and $\varepsilon_{1}=2.0$. The increasing behavior in the streamlines is depicted here. Similar impact can also be seen for $\varepsilon_{2}=1.0$ and $\varepsilon_{2}=2.0$ in Figures $6(\mathrm{e})$ and $6(\mathrm{f})$. Figure $6(\mathrm{~g})$ and $6(\mathrm{~h})$ display the streamlines for $\varepsilon_{3}=1.0$ and $\varepsilon_{3}=2.0$. A decreasing impact in streamlines is observed here.

Figure 7(a-d) presents the analysis of analytical and numerical techniques for velocity, thermal, concentration, and microorganisms' motile density functions. A close agreement is found here. 


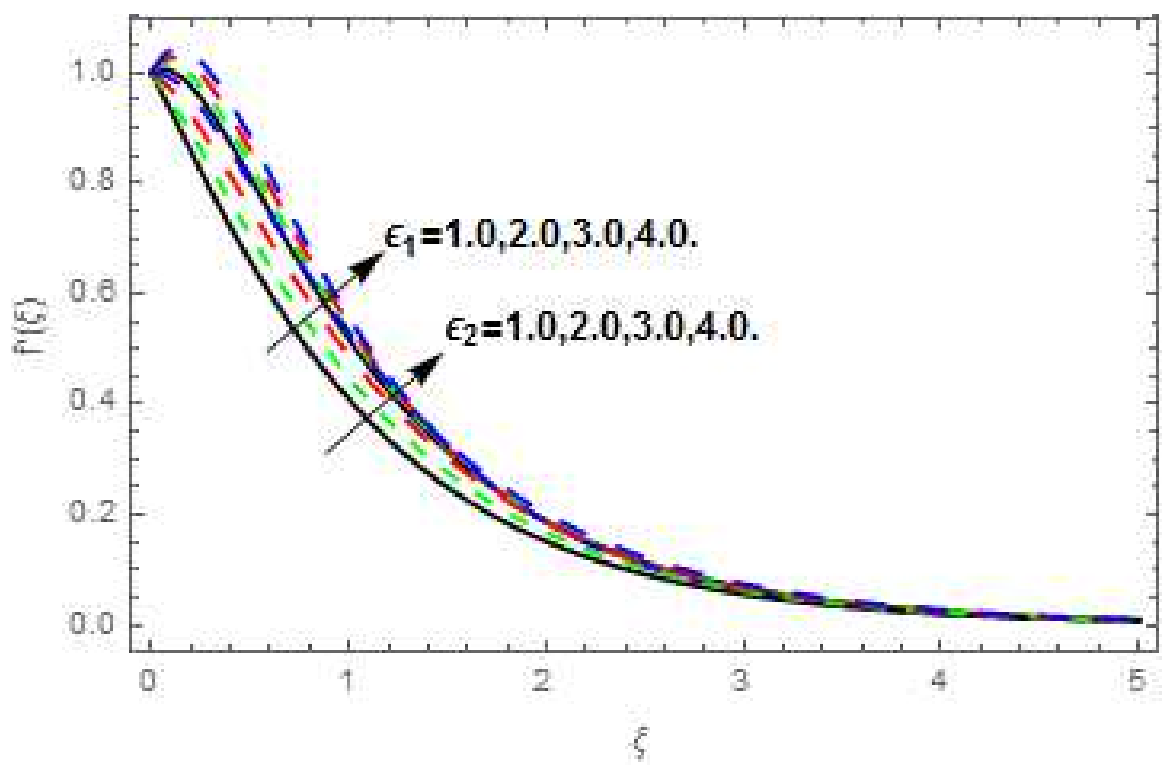

Figure 2(a): $f^{\prime}(\xi)$ versus $\varepsilon_{1}$ and $\varepsilon_{2}$.

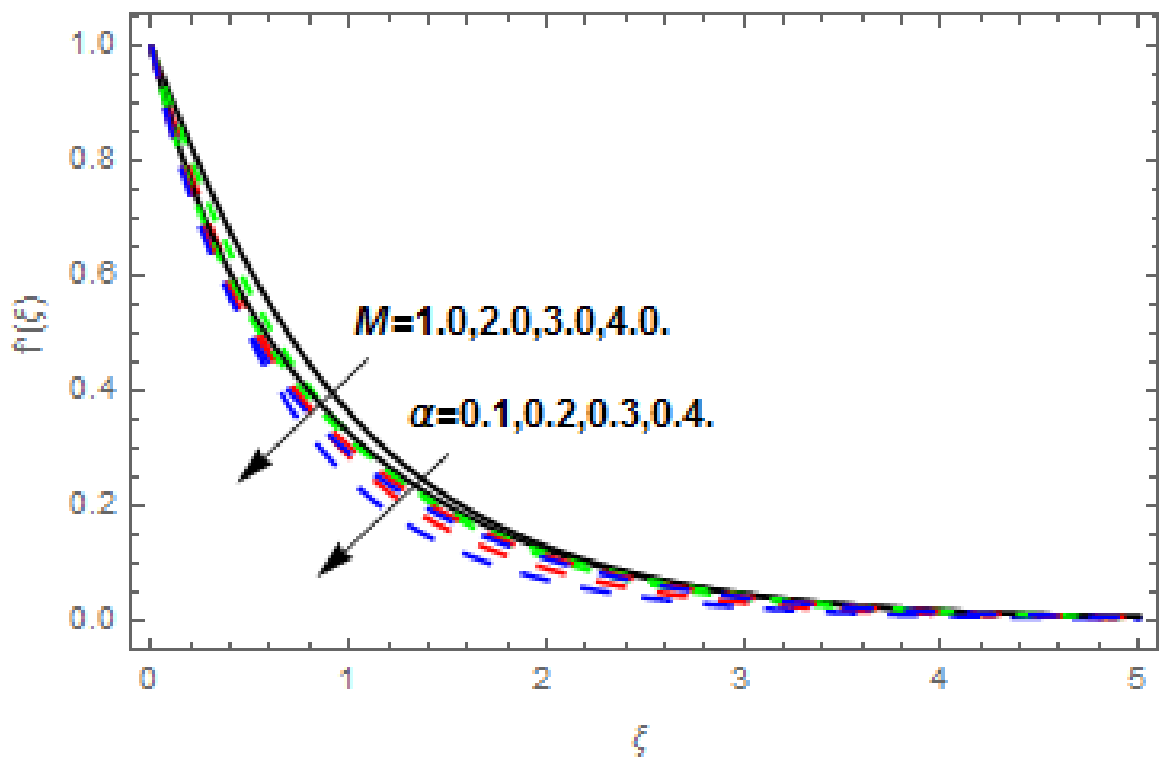

Figure 2(b): $f^{\prime}(\xi)$ versus $M$ and $\alpha$. 


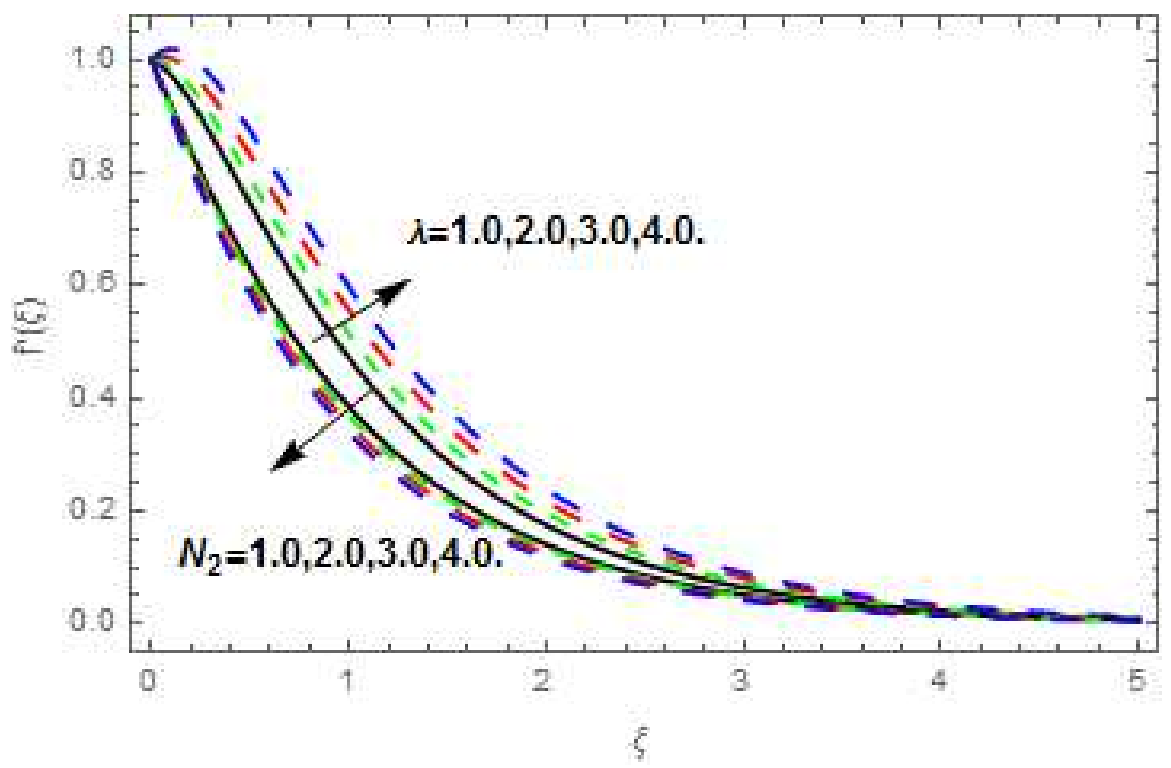

Figure 2(c): $f^{\prime}(\xi)$ versus $\lambda$.

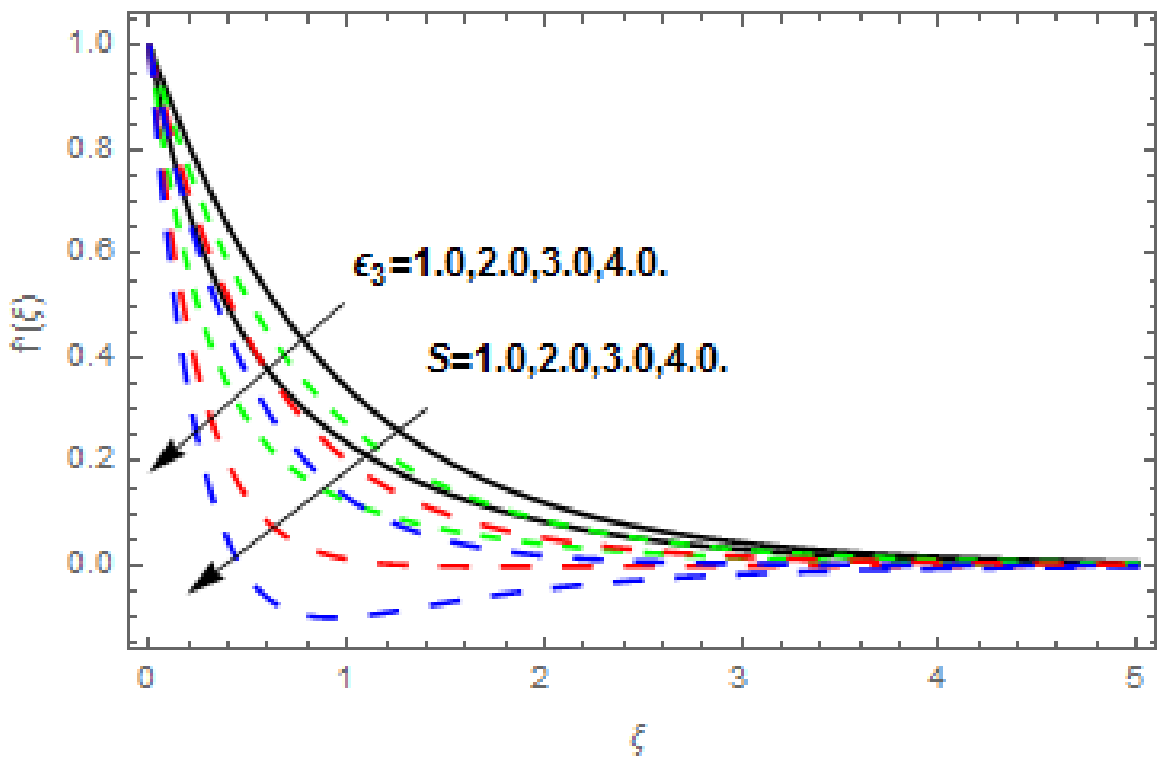

Figure 2(d): $f^{\prime}(\xi)$ versus $\varepsilon_{3}$ and $S$. 


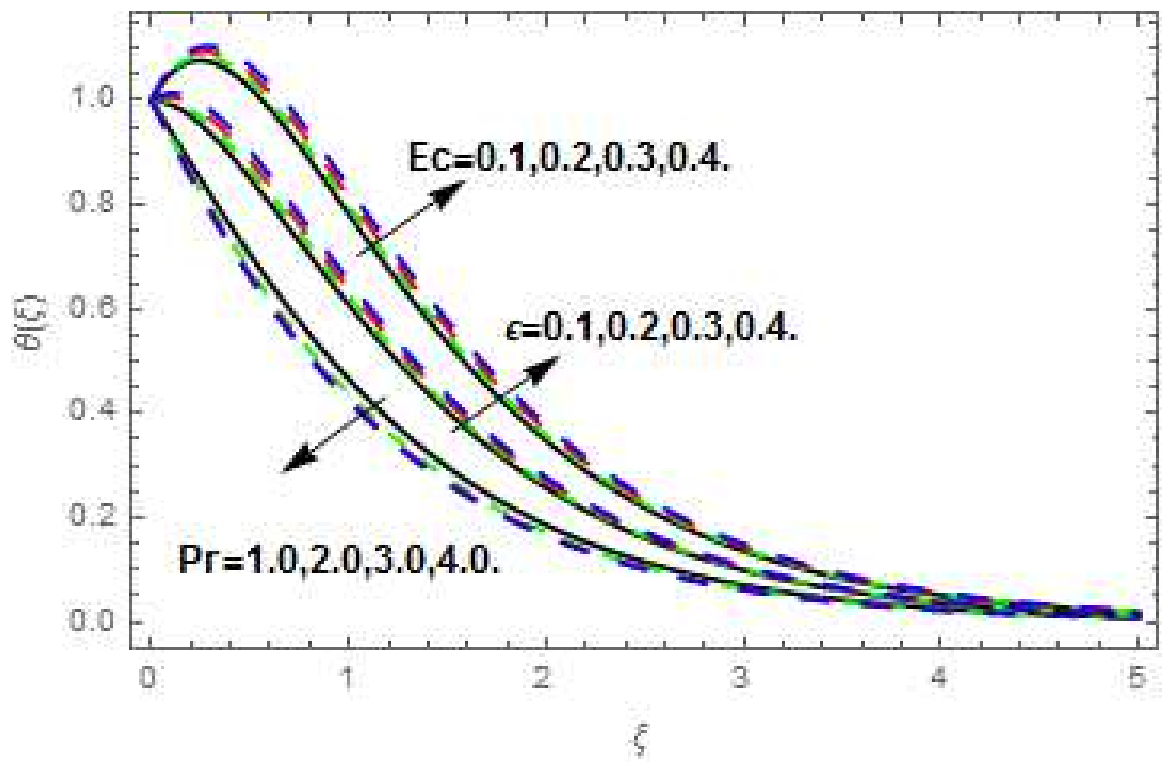

Figure 3: $\theta(\xi)$ versus $E c$.

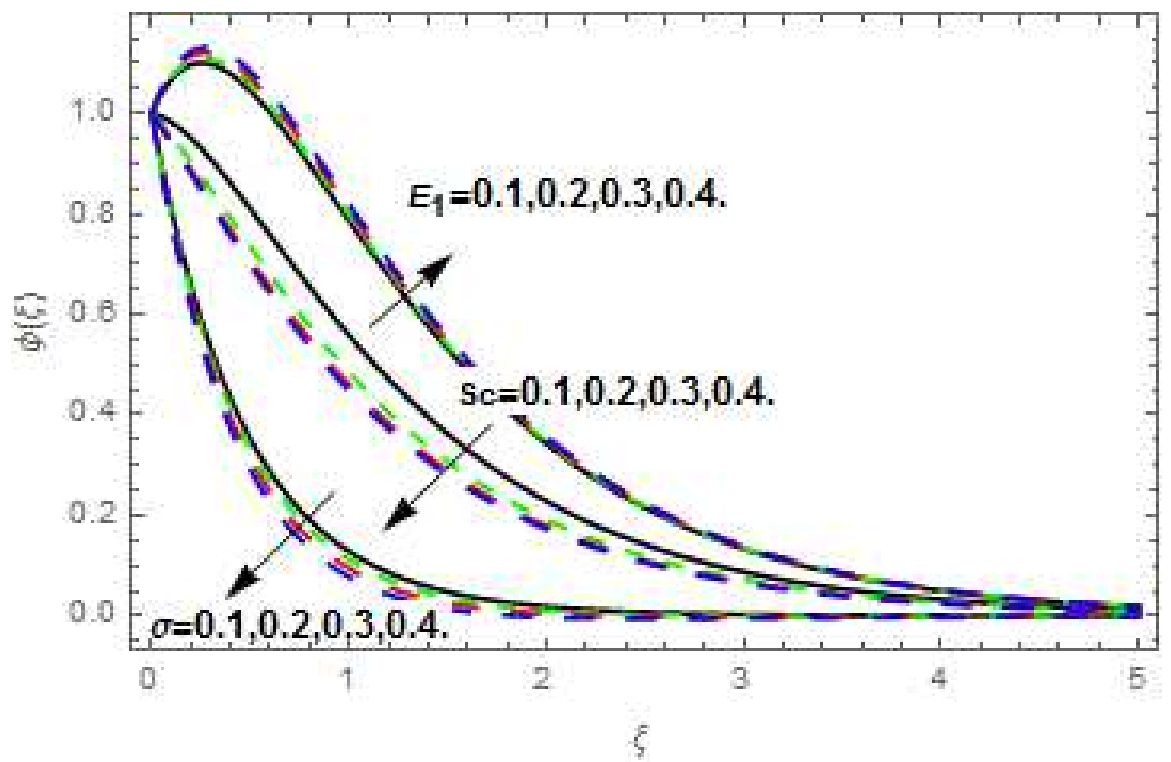

Figure 4: $\phi(\xi)$ versus $E_{1}, S c$ and $\sigma$. 


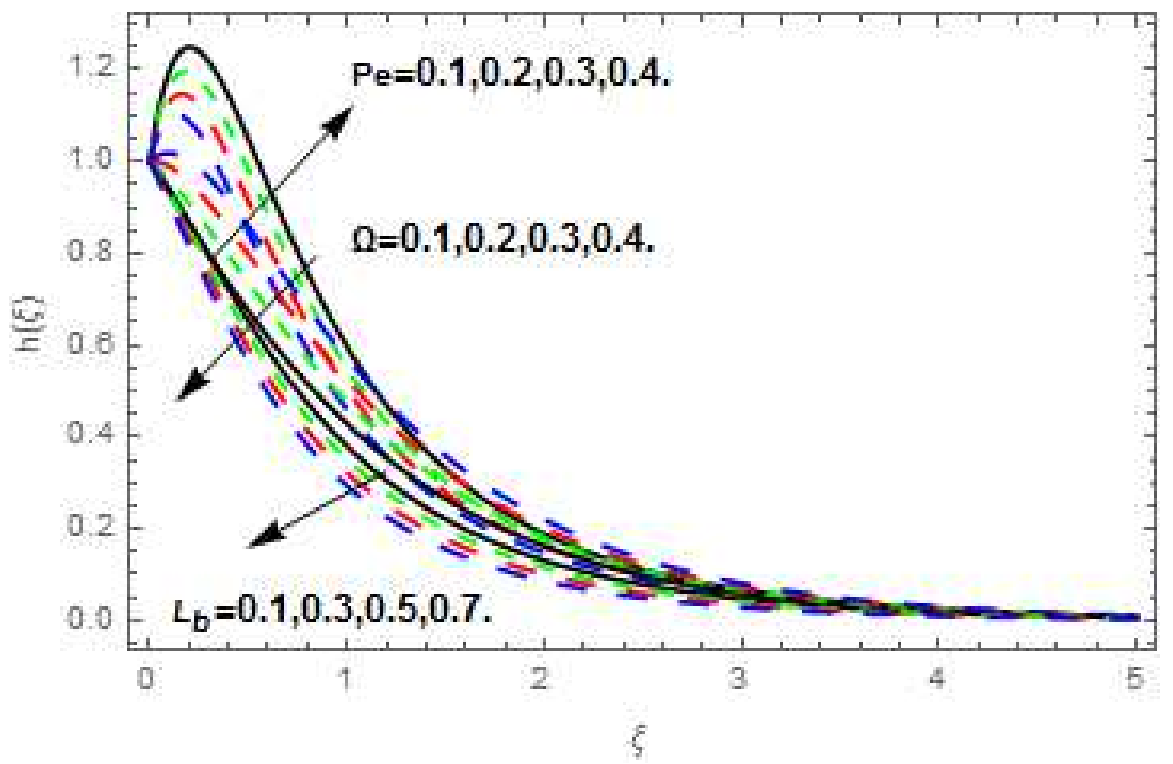

Figure 5: $h(\xi)$ versus $L_{b}, P e$ and $\Omega$.

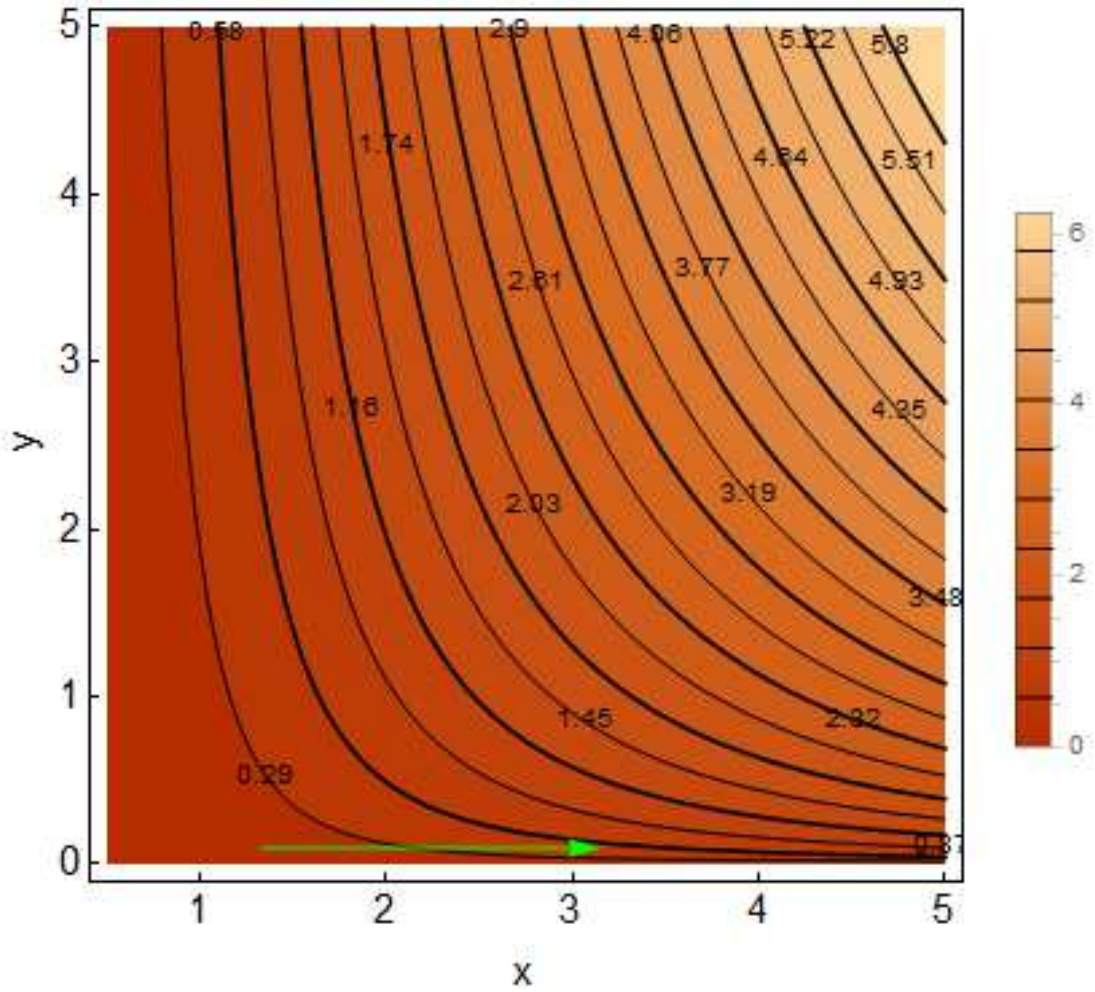

Figure 6(a): Streamlines for steady case. 


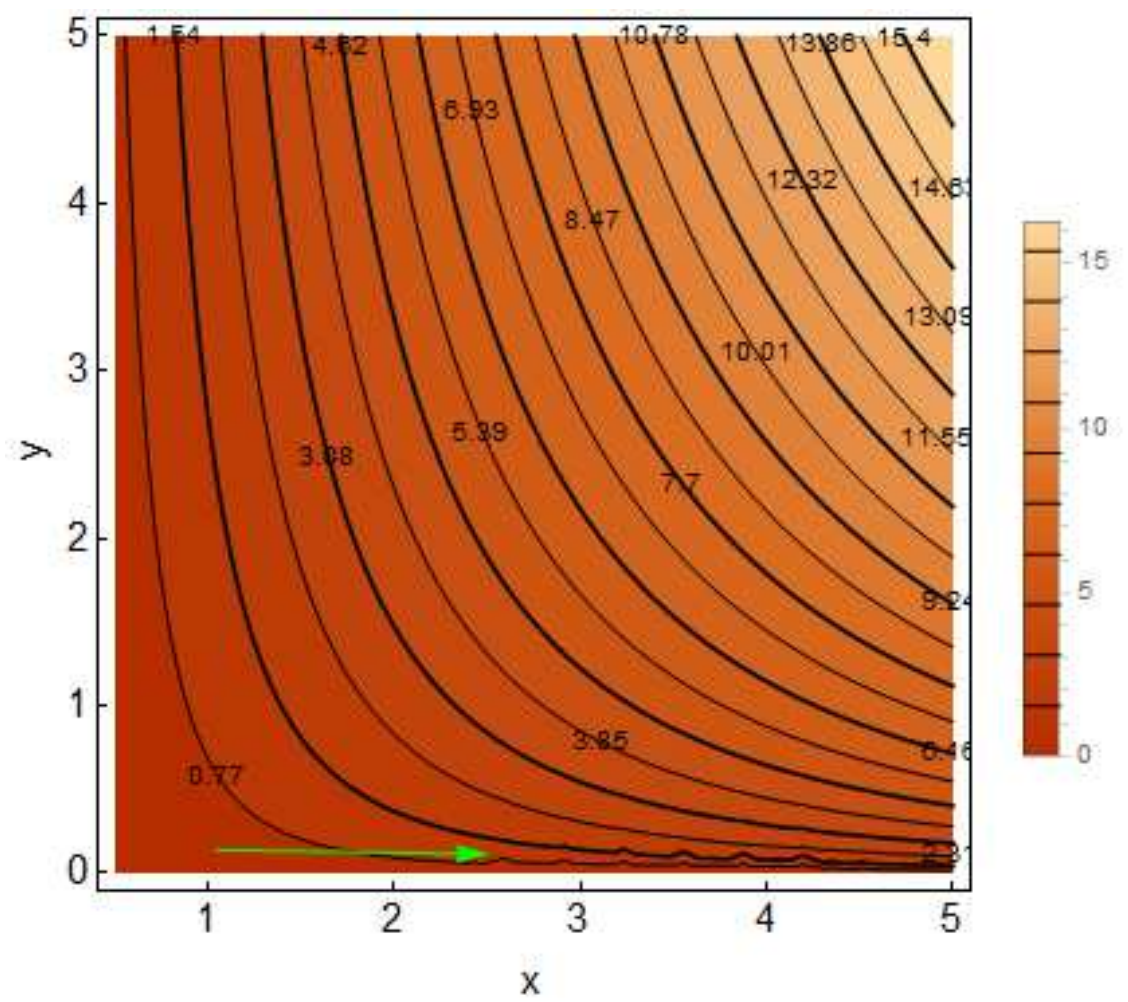

Figure 6(b): Streamlines for unsteady case.

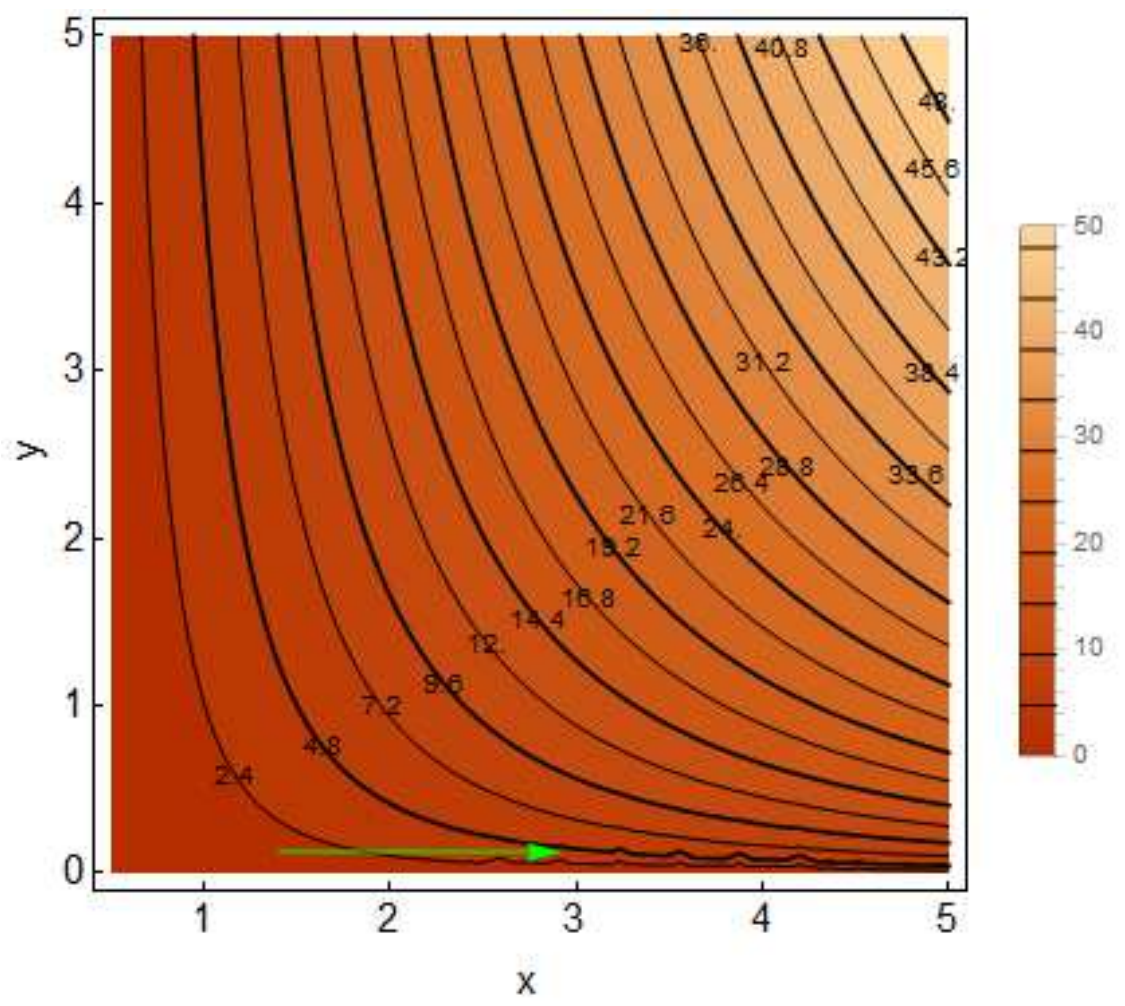


Figure 6(c): Streamlines for $\varepsilon_{1}=1.0$.

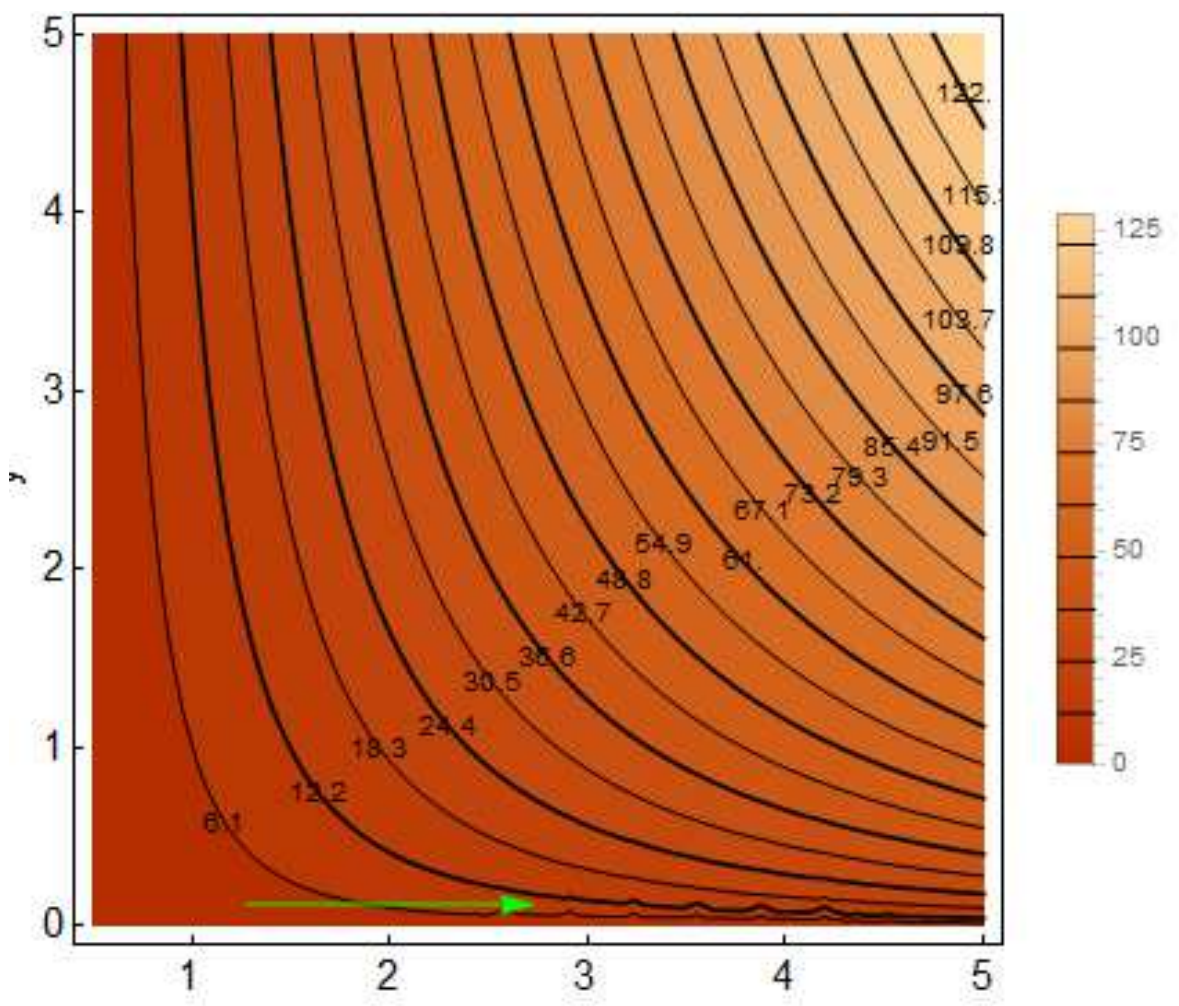

Figure 6(d): Streamlines for $\varepsilon_{1}=2.0$. 


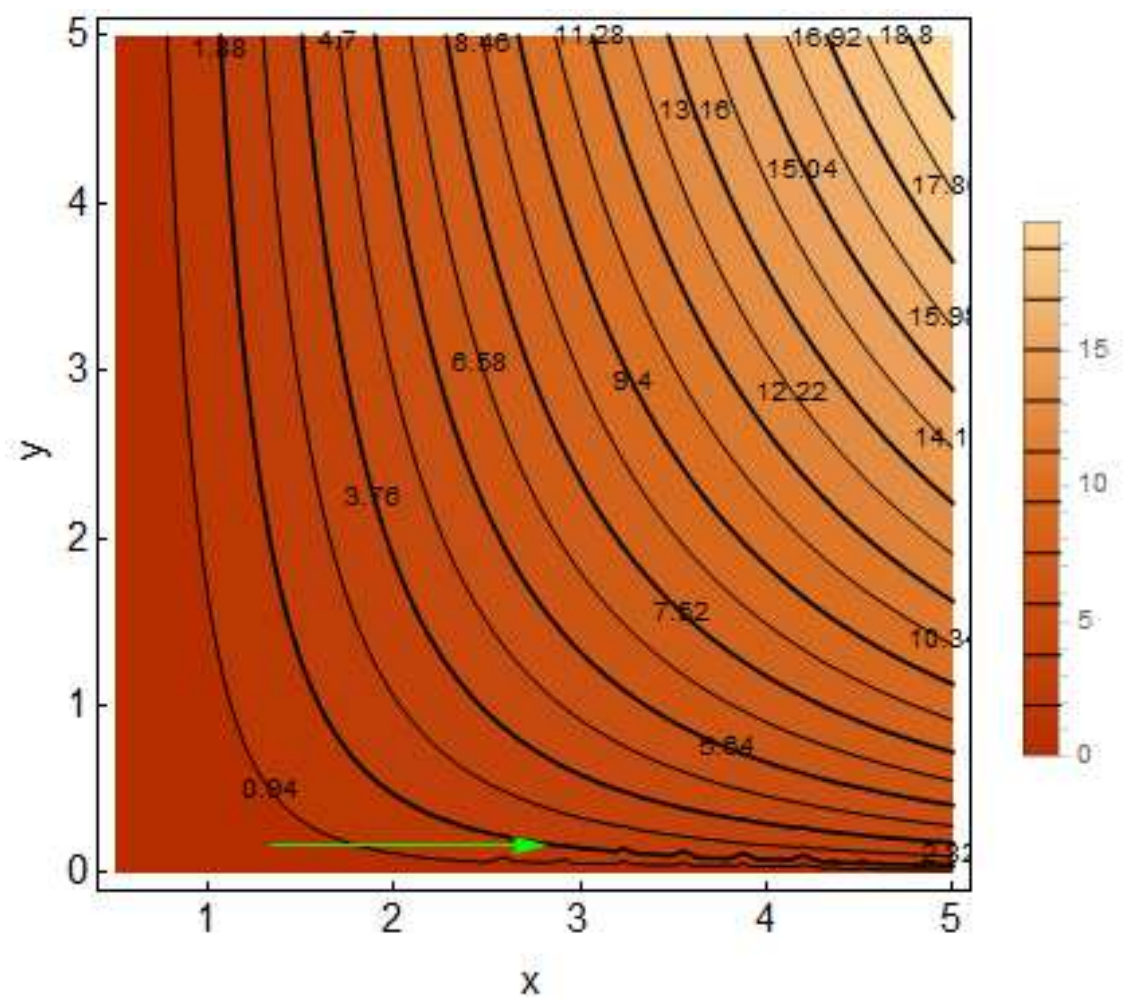

Figure 6(e): Streamlines for $\varepsilon_{2}=1.0$.

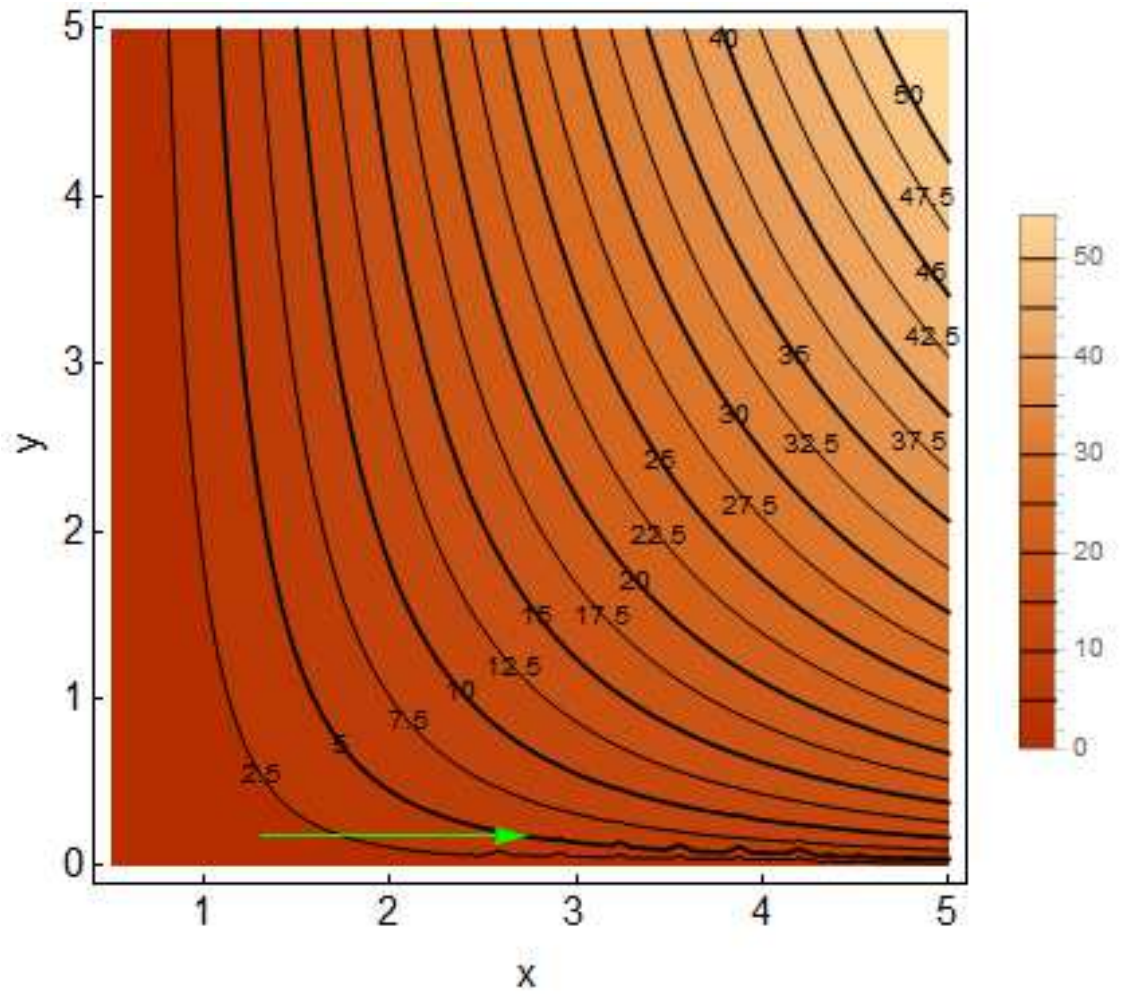


Figure 6(f): Streamlines for $\varepsilon_{2}=2.0$.

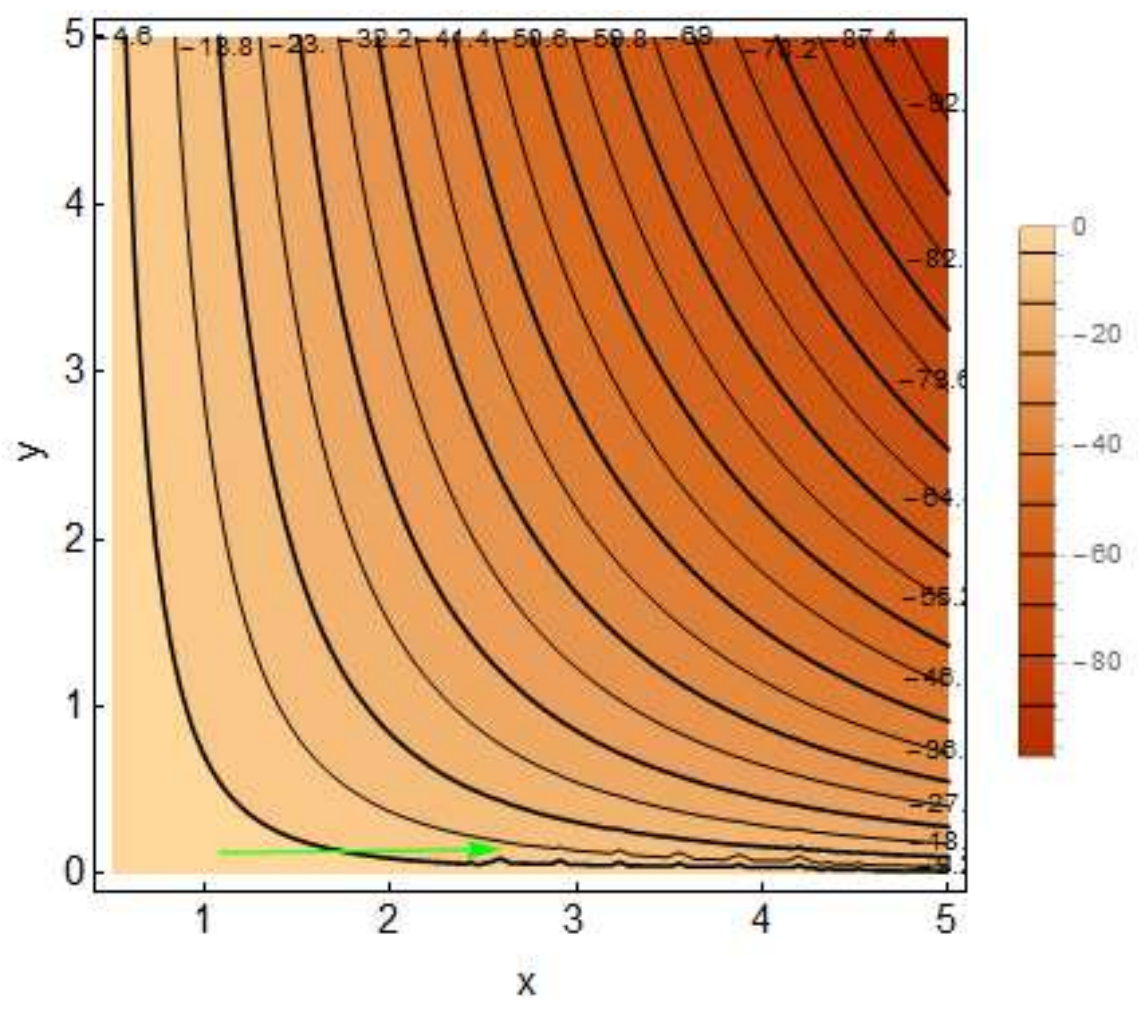

Figure 6(g): Streamlines for $\varepsilon_{3}=1.0$. 


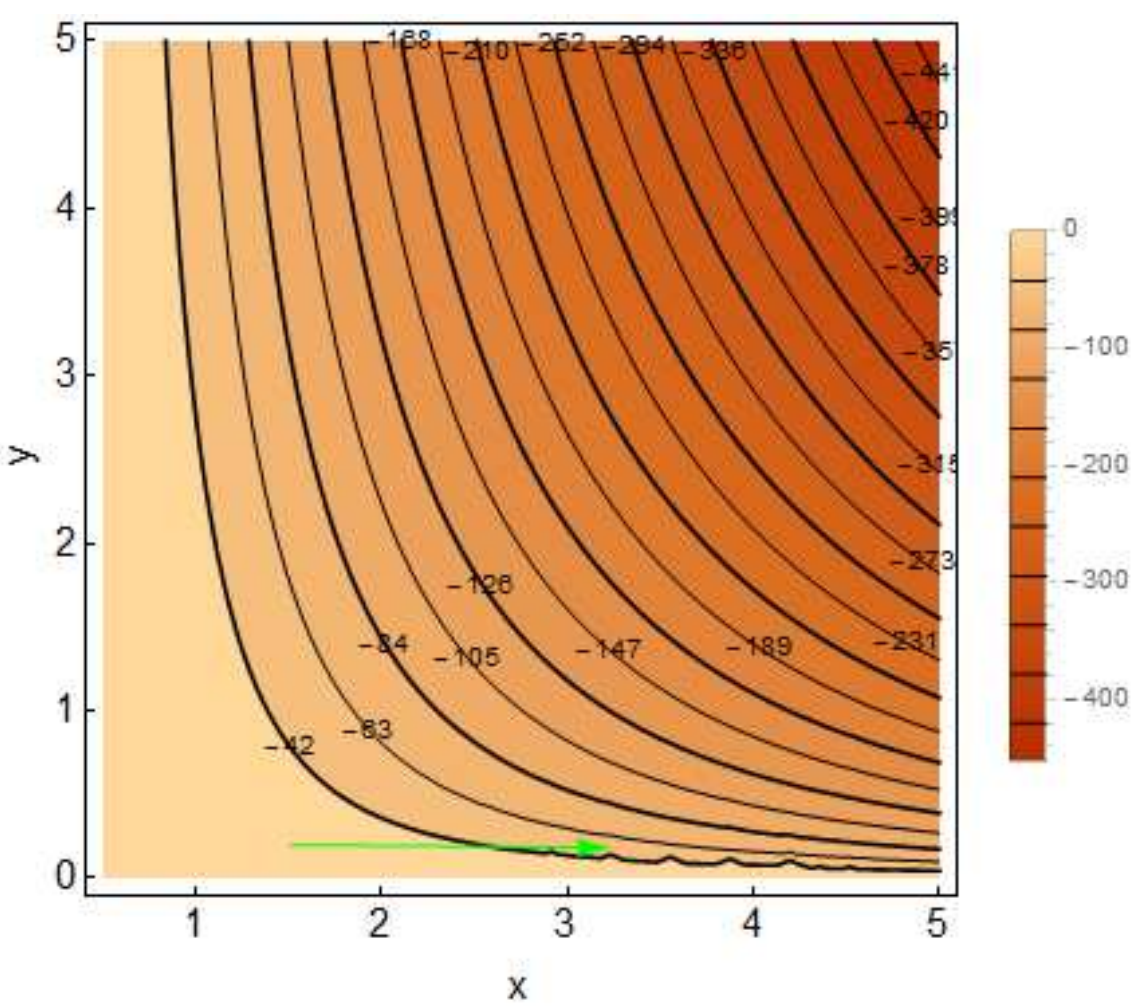

Figure 6(h): Streamlines for $\varepsilon_{3}=2.0$.

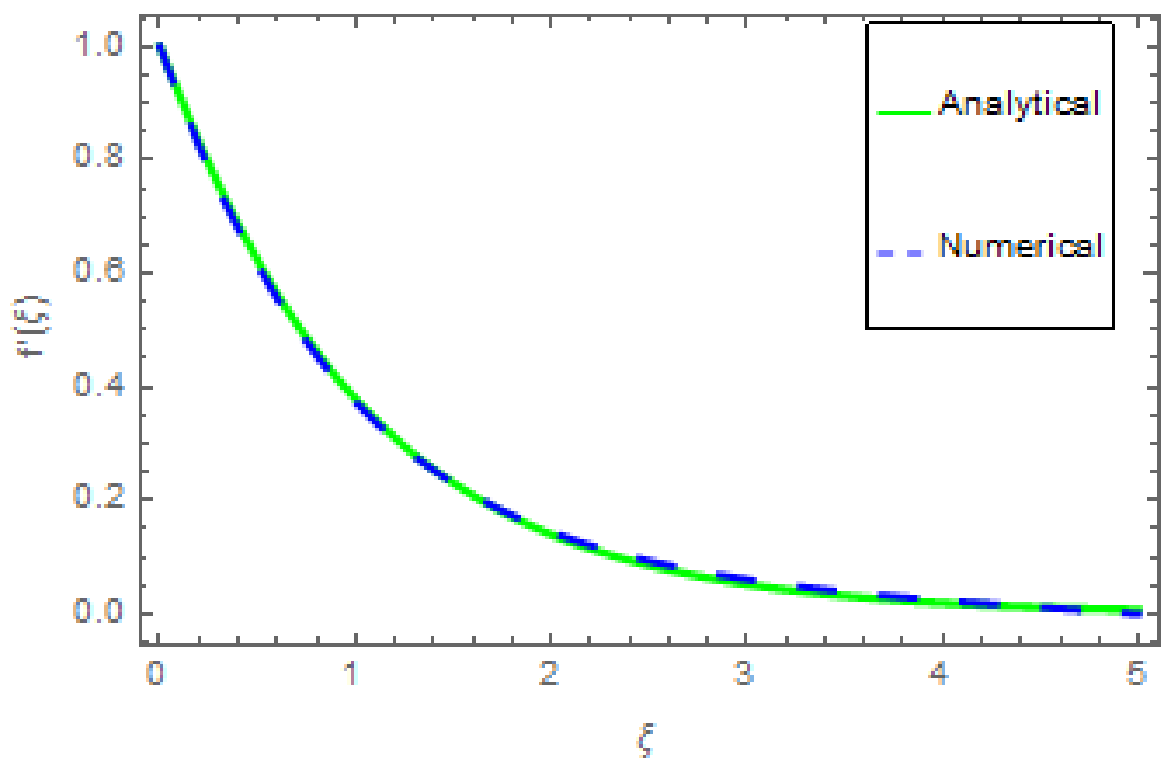

Figure 7(a): Analytical and numerical comparison for velocity function. 


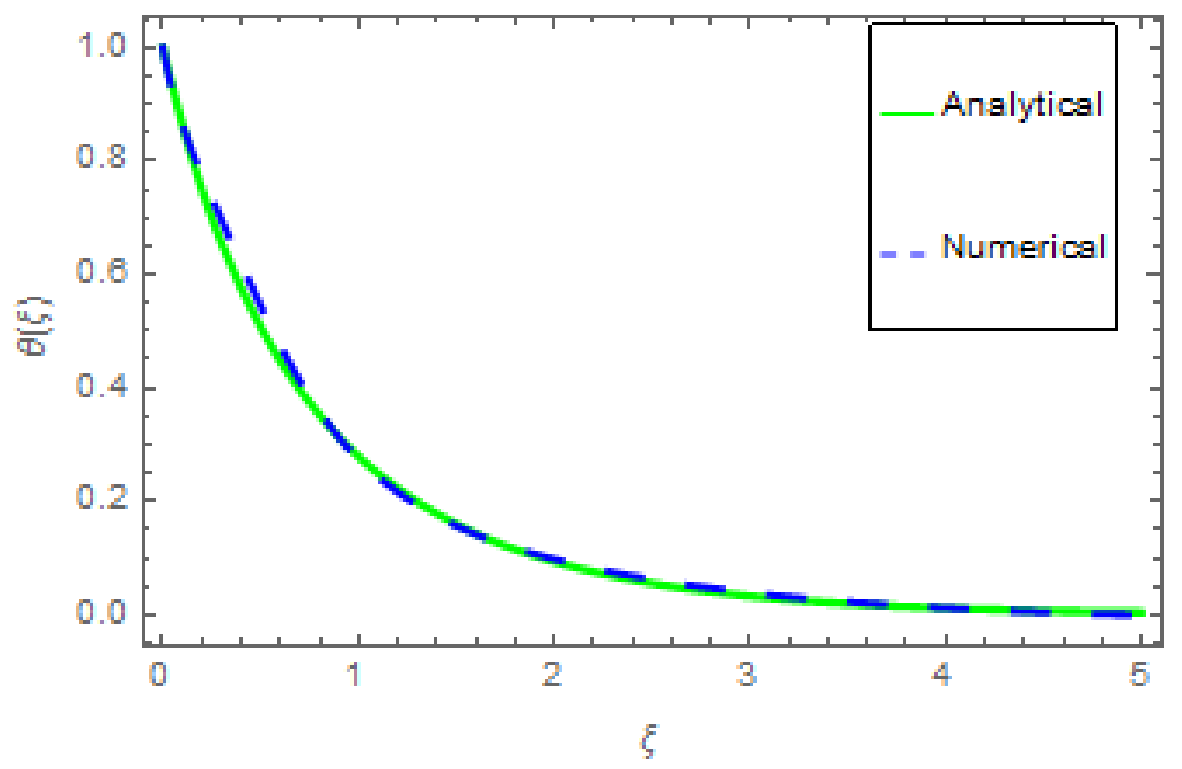

Figure 7(b): Analytical and numerical comparison for thermal function.

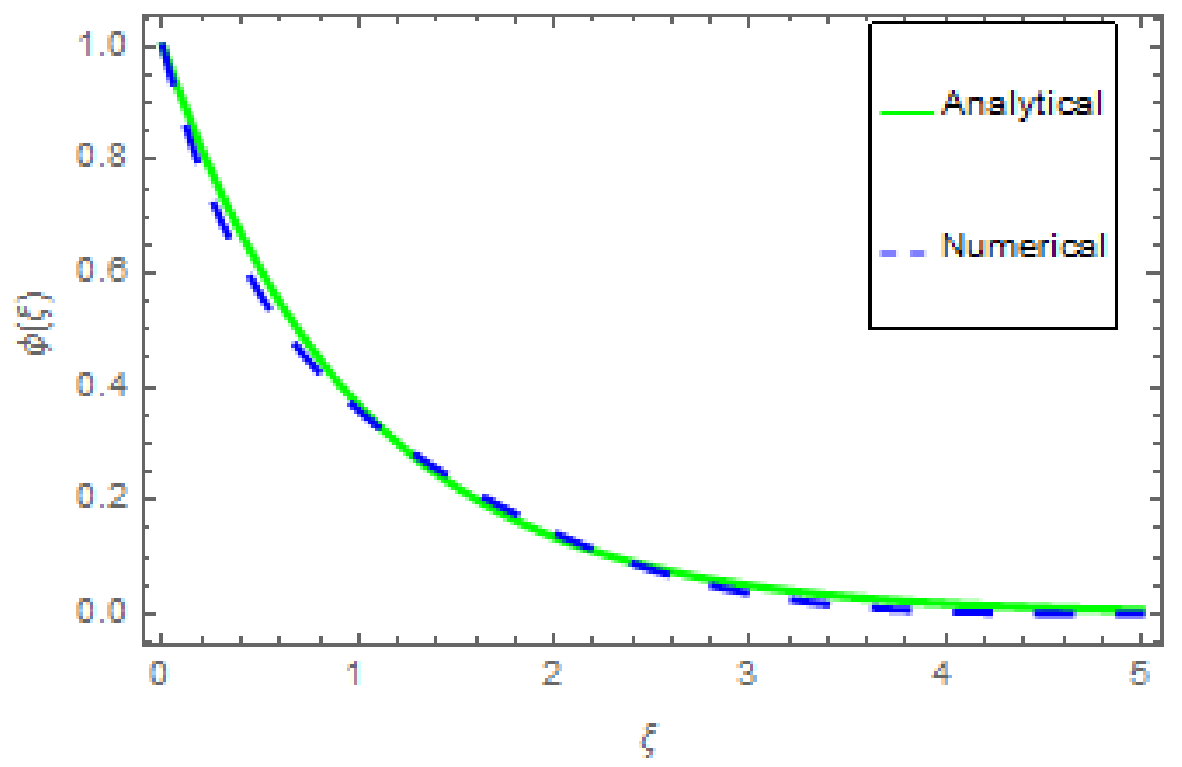

Figure 7(c): Analytical and numerical comparison for concentration function. 


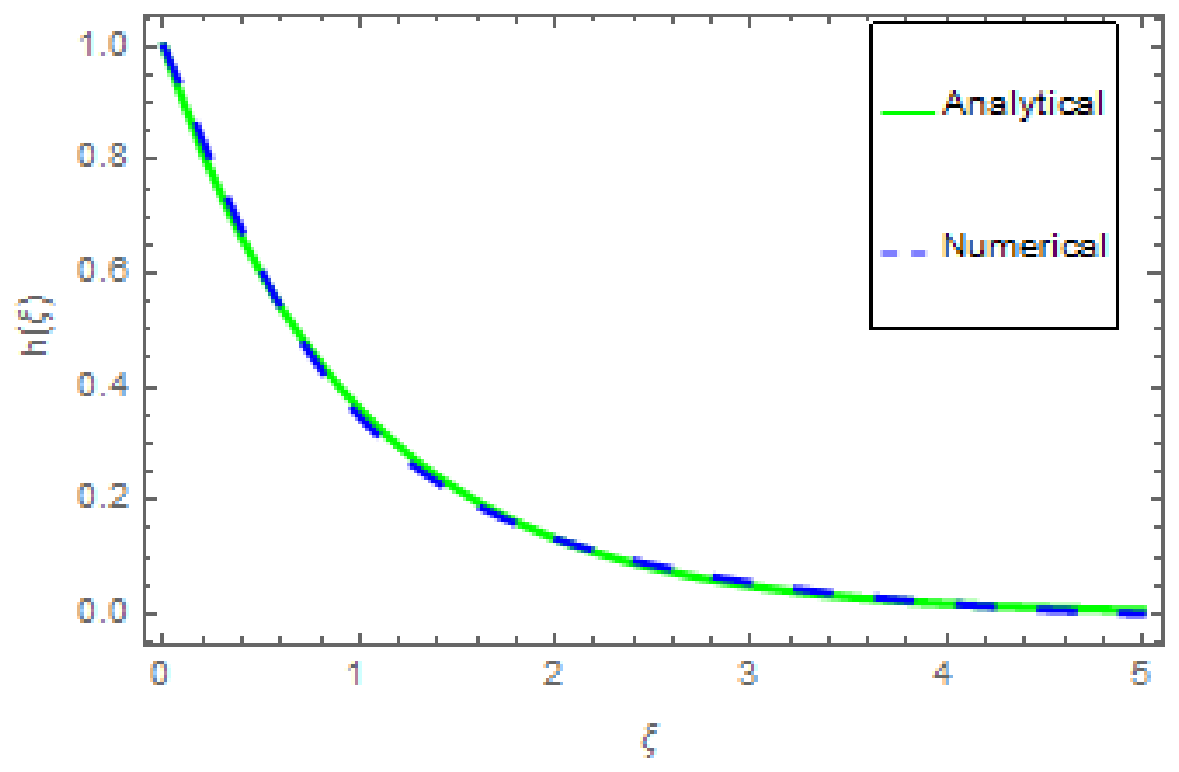

Figure 7(d): Analytical and numerical comparison for motile density of microorganisms function.

\section{Conclusion}

An analytical and numerical solution of an unsteady and incompressible flow of motile gyrotactic microorganisms suspended in a third grade nanofluid through a stretching surface is done with the help of incorporated codes in MATHEMATICA. Convergence of HAM is presented. The outcomes of the embedded factors on the nanofluid flow are presented through figures. Leading arguments of the extant study are:

- Velocity function increases for higher material parameters, and mixed convection parameter.

- The velocity function declines for higher bioconvective Rayleight number, magnetic parameter and viscosity parameter, third grade fluid and unsteady parameters.

- Thermal function heightens for higher Eckert number and thermal conductivity constant

- The thermal function decays for higher Prandtl number.

- Concentration function heightens for activation energy parameter.

- The concentration function reduces for greater Schmidt number, and chemical reaction parameter.

- Density function of microorganisms escalates for escalating Peclet number. 
- The density function of microorganisms reduces for Lewis number and concentration difference of microorganisms.

- A quit change behavior in streamlines between the steady case and unsteady case of the present analysis is found. 


\section{References}

1. S.U.S. Choi, Enhancing thermal conductivity of fluids with nanoparticles, ASMEPublications-Fed. 231 (1995) 99-106.

2. J. Boungiorno, Convective transport in nanofluids, J. Heat Transf. 128 (2010) 240-250.

3. M. Turkyilmazoglu, Flow of nanofluid plane wall jet and heat transfer, European J, Mech. B/Fluid. 59 (2016) 18-24.

4. A. Baslem, G. Sowmya, B.J. Gireesha, B.C. Prasannakumara, M. Rahimi-Gorji, N.M. Hoang, Analysis of thermal behavior of a porous fin fully wetted with nanofluids: convection and radiation, J. Mol. Liq. 307 (2020) 112920.

5. R. Muhammad, M.I. Khan, N.B. Khan, M. Jameel, Magnetohydrodynamics (MHD) radiated nanomaterial viscous material flow by a curved surface with second order slip and entropy generation, Comput. Meth. Prog. Biomedi. 189 (2020) 105294

6. G. Sowmya, B.J. Gireesha, S. Sindhu, B.C. Prasannakumara, Investigation of Ti6Al4V and AA 7075 alloy embedded nanofluid flow over longitudinal porous fin in the presence of internal heat generation and convective condition, Commu. Theoret. Phys. 72 (2020) 025004 .

7. H. Waqas, S.A. Shehzad, S.U. Khan, M. Imran, Novel numerical computations on flow of nanoparticles in porous rotating disk with multiple slip effects and microorganisms, J. Nanofluids 8 (2019) 1423-1432.

8. S. Ahmad, M.I. Khan, T. Hayat, M.I. Khan, A. Alsaedi, Entropy generation optimization, and unsteady squeezing flow of viscous fluid with five different shapes of nanoparticles, Colloid. Surf. A: Physicochem. Eng. Aspect. 554 (2018) 197-210.

9. B.J. Gireesha, K.G. Kumar, G.K. Ramesh, B.C. Prasannakumara, Nonlinear convective heat and mass transfer of Oldroyd-B nanofluid over a stretching sheet in the presence of uniform heat source/sink, Results Phys. 9 (2018) 1555-1563.

10. Dawar A, Shah Z, Islam S. Mathematical modeling and study of MHD flow of Williamson nanofluid over a nonlinear stretching plate with activation energy. Heat Transfer. 2020;1-13. https://doi.org/10.1002/htj.21992.

11. Zahir Shah, Luthais B. McCash, Abdullah Dawar, Ebenezer Bonyah. Entropy optimization in Darcy-Frochheimer mhd flow of water based copper and silver 
nanofluids with joule heating and viscous dissipation effects. AIP Advances 10, 065137 (2020); https://doi.org/10.1063/5.0014952.

12. Dawar, A., Shah, Z., Kumam, P. et al. Chemically reactive MHD micropolar nanofluid flow with velocity slips and variable heat source/sink. Sci Rep 10, 20926 (2020). https://doi.org/10.1038/s41598-020-77615-9.

13. M. Turkyilmazoglu, Single phase nanofluids in fluid mechanics and their hydrodynamic linear stability analysis, Comput. Methods Prog. Biomed. 187 (2020) 105171.

14. Y.M. Chu, M. Israr Ur Rehman, M.I. Khan, S. Nadeem, S. Kadry, Z. Abdelmalek, N. Abbas, Transportation of heat and mass transport in hydromagnetic stagnation point flow of Carreau nanomaterial: Dual simulations through Runge-Kutta Fehlberg technique, Int. $\begin{array}{llllll}\text { Commu. Heat } & \text { Mass } & \text { Transf. } & 118 \text { (2020) }\end{array}$ https://doi.org/10.1016/j.icheatmasstransfer.2020.104858.

15. M.G. Reddy, M.S. Rani, K.G. Kumar, B.C. Prasannakumara, Cattaneo-Christov heat flux and non-uniform heat-source/sink impacts on radiative Oldroyd-B two-phase flow across a cone/wedge, J. Braz. Soc. Mech. Sci. Eng. 40 (2018) 95.

16. H. Waqas, S.U. Khan, M. Imran, M.M. Bhatti, Thermally developed Falkner-Skan bioconvection flow of a magnetized nanofluid in the presence of motile gyrotactic microorganism: Buongiorno's nanofluid model, Phys. Scr. 94 (2019) 115304.

17. M.I. Khan, S. Kadry, Y.M. Chu, W.A. Khan, A. Kumar, Exploration of Lorentz force on a paraboloid stretched surface in flow of Ree-Eyring nanomaterial, J. Mater. Resear. Techn. 9 (2020) 10265-10275.

18. S.U. Khan, A. Rauf, S.A. Shehzad, Z. Abbas, T. Javed, Study of bioconvection flow in Oldroyd-B nanofluid with motile organisms and effective Prandtl approach, Phys. A: Statist. Mech. Appl. 527 (2019) 121179.

19. M.I. Khan, F. Alzahrani, A. Hobiny, Z. Ali, Estimation of entropy generation in CarreauYasuda fluid flow using chemical reaction with activation energy, J. Mater. Resear. Techn. 9 (2020) 9951-9964.

20. T. Chinyoka, O.D. Makinde, Unsteady hydromagnetic flow of a reactive variable viscosity third-grade fluid in a channel with convective cooling, Int. J. Numer. Methods Fluids 69 (2012) 353-365. 
21. T. Hayat, R. Naz, S. Asghar, S. Mesloub, Soret-Dufour effects on three-dimensional flow of third grade fluid, Nucl. Eng. Des. 243 (2012) 1-14.

22. B. Sahoo, Y. Do, Effects of slip on sheet driven flow and heat transfer of a third grade fluid past a stretching sheet, Int. Commun. Heat Mass Transfer 37 (2010) 1064-1071.

23. S. Abbasbandy, T. Hayat, On series solution for unsteady boundary layer equations in a special third grade fluid, Commun. Nonlinear Sci. Numer. Simul. 16 (2011) 3140-3148.

24. T. Hayat, Z. Iqbal, M. Mustafa, A.A. Hendi, Melting heat transfer in the stagnation point flow of third-grade fluid past a stretching sheet with viscous dissipation, Therm. Sci. 17 (3) (2013) 865-875.

25. A. Shafiq, M. Nawaz, T. Hayat, A. Alsaedi, Magnetohydrodynamic axisymmetric flow of a third-grade fluid between two porous disks, Br. J. Chem. Eng. 30 (3) (2013) 599-609.

26. M. Hatami, J. Hatami, D.D. Ganji, Computer simulation of MHD blood conveying gold nanoparticles as a third grade non-Newtonian nanofluid in a hollow porous vessel, Comput. Methods Program. Biomed. (2013).

27. T. Hayat, S.A. Shehzad, M. Qasim, S. Asghar, A. Alsaedi, Thermally stratified radiative flow of third grade fluid over a stretching surface, J. Thermophys. Heat Transfer 28 (2014) 155-161.

28. S.A. Gaffar, V.R. Prasad, O.A. Be'g, M.H.H. Khan, K. Venkatadri, Radiative and magnetohydrodynamics flow of third-grade viscoelastic fluid past an isothermal inverted cone in the presence of heat generation/absorption, J. Braz. Soc. Mech. Sci. Eng. (2018), https://doi.org/10.1007/s40430-018-1049-0.

29. M. Sajid, M. Mughees, N. Ali, A theoretical analysis of blade coating for third-grade fluid, J. Plas. Film Coat. (2019), https:// doi.org/10.1177/8756087919828417.

30. M. Waqas, M. Ijaz Khan, T. Hayat, S. Farooq, A. Alsaedi, Interaction of thermal radiation in hydromagnetic viscoelastic nanomaterial subject to gyrotactic microorganisms, Appl. Nanosci. (2019), https://doi.org/10.1007/s13204-018-00938-7.

\section{Acknowledgements}

"The authors acknowledge the financial support provided by the Center of Excellence in Theoretical and Computational Science (TaCS-CoE), KMUTT". Moreover, this research project is supported by Thailand Science Research and Innovation (TSRI) Basic Research Fund: Fiscal year 2021 under project number 64A306000005. 
A.D, P.K and Z.S modeled and solved the problem. A.D and S.I wrote the manuscript. Z.S and $P . K$ contributed in the numerical computations and plotting the graphical results. All authors finalized the manuscript after its internal evaluation.

Additional Information

Competing Interests: The authors declare no competing interests 
Figures
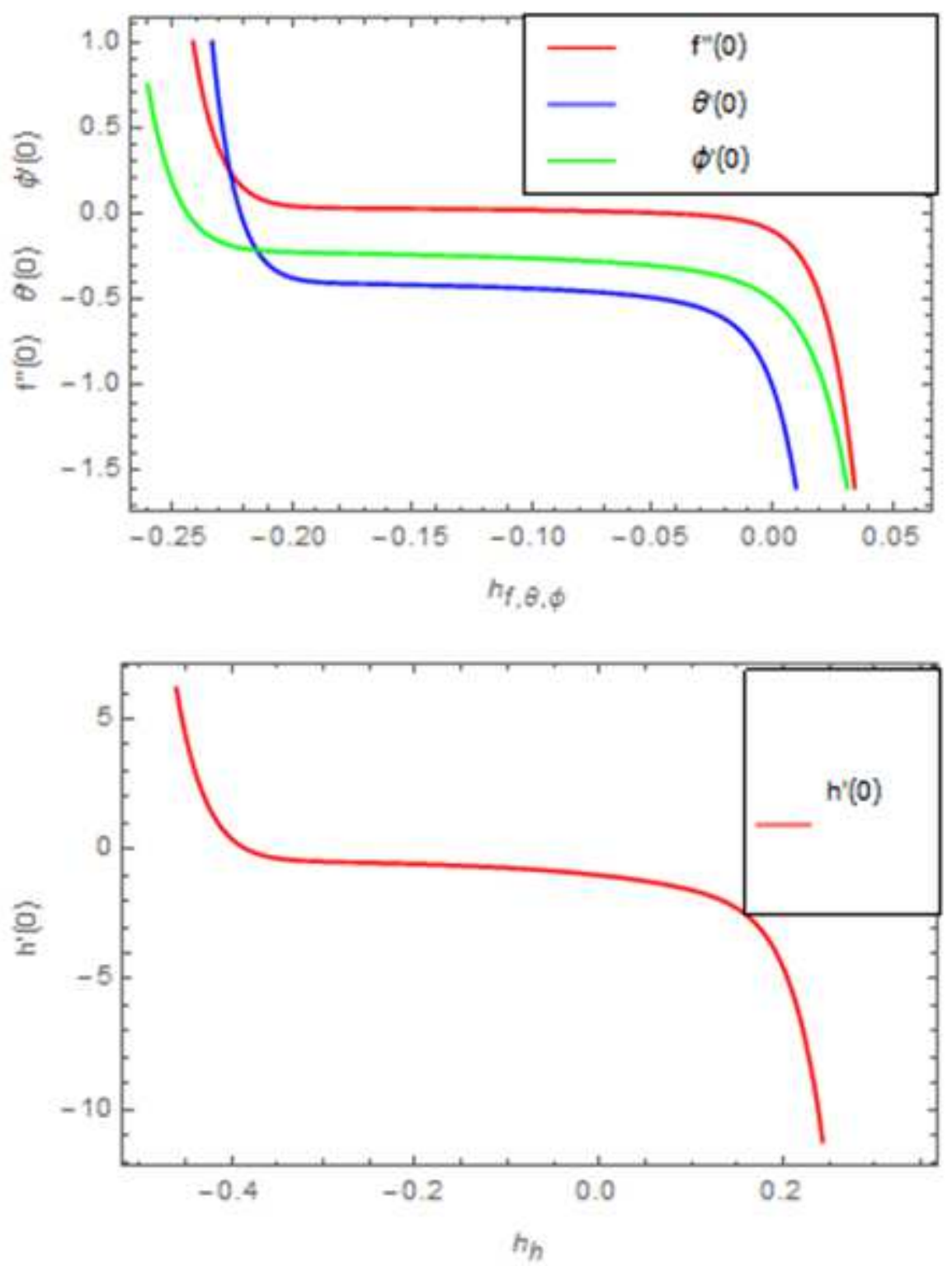

Figure 1

Please see the manuscript PDF file for the full caption 

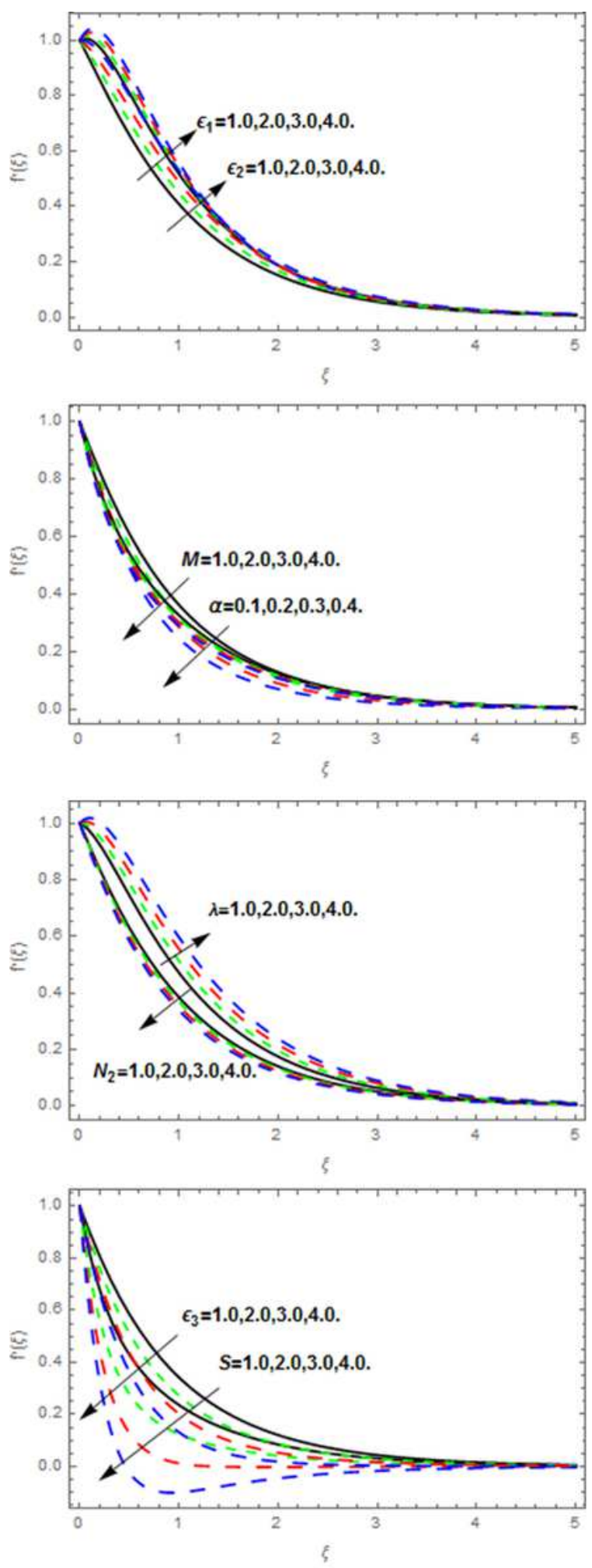

Figure 2

Please see the manuscript PDF file for the full caption 


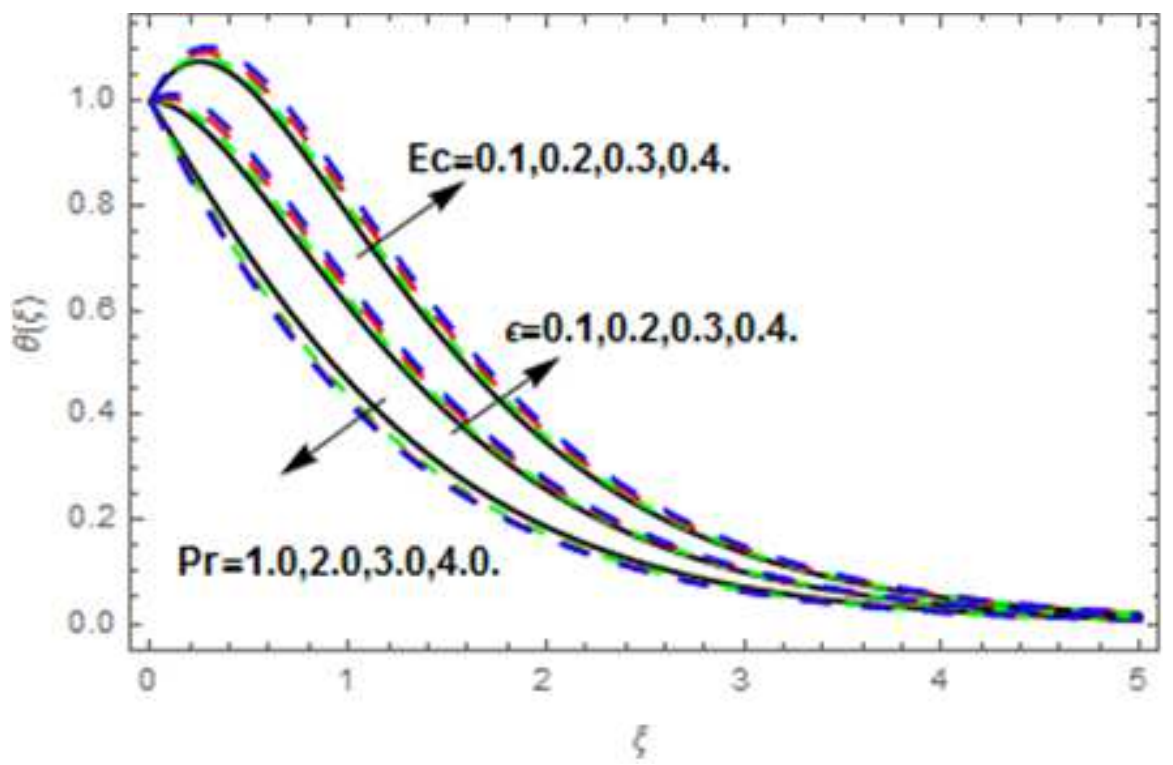

Figure 3

Please see the manuscript PDF file for the full caption

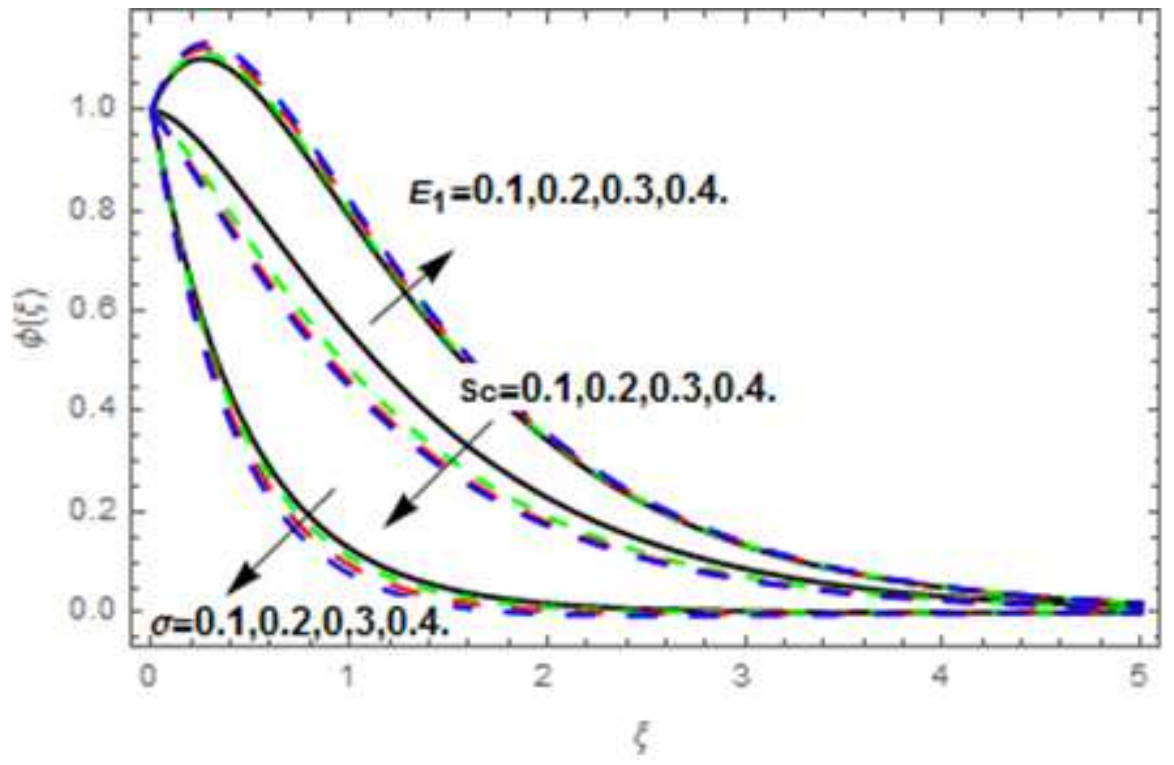

Figure 4

Please see the manuscript PDF file for the full caption 


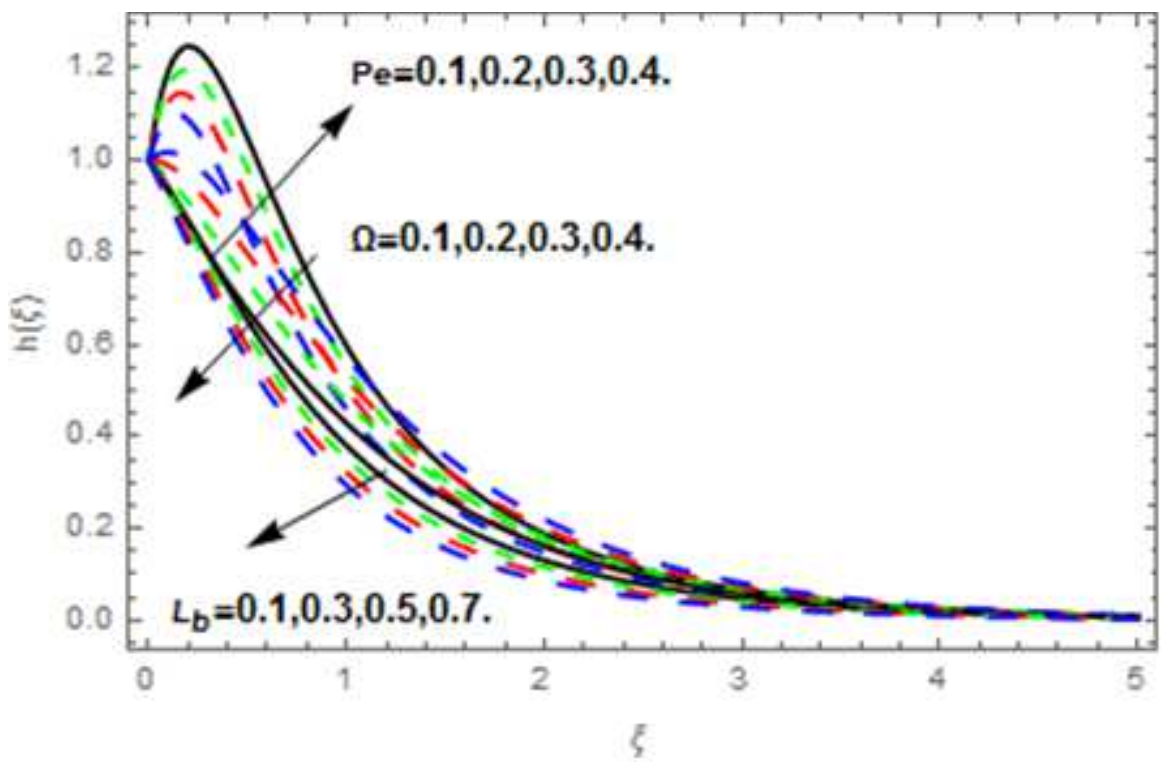

Figure 5

Please see the manuscript PDF file for the full caption 

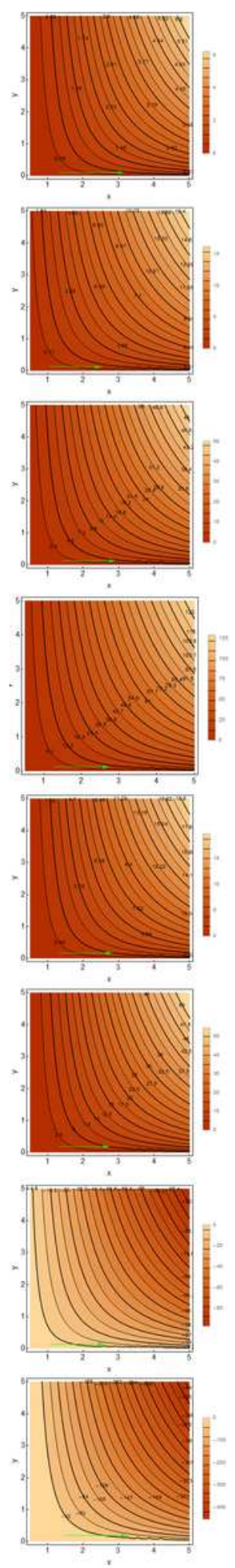

Figure 6

Please see the manuscript PDF file for the full caption 

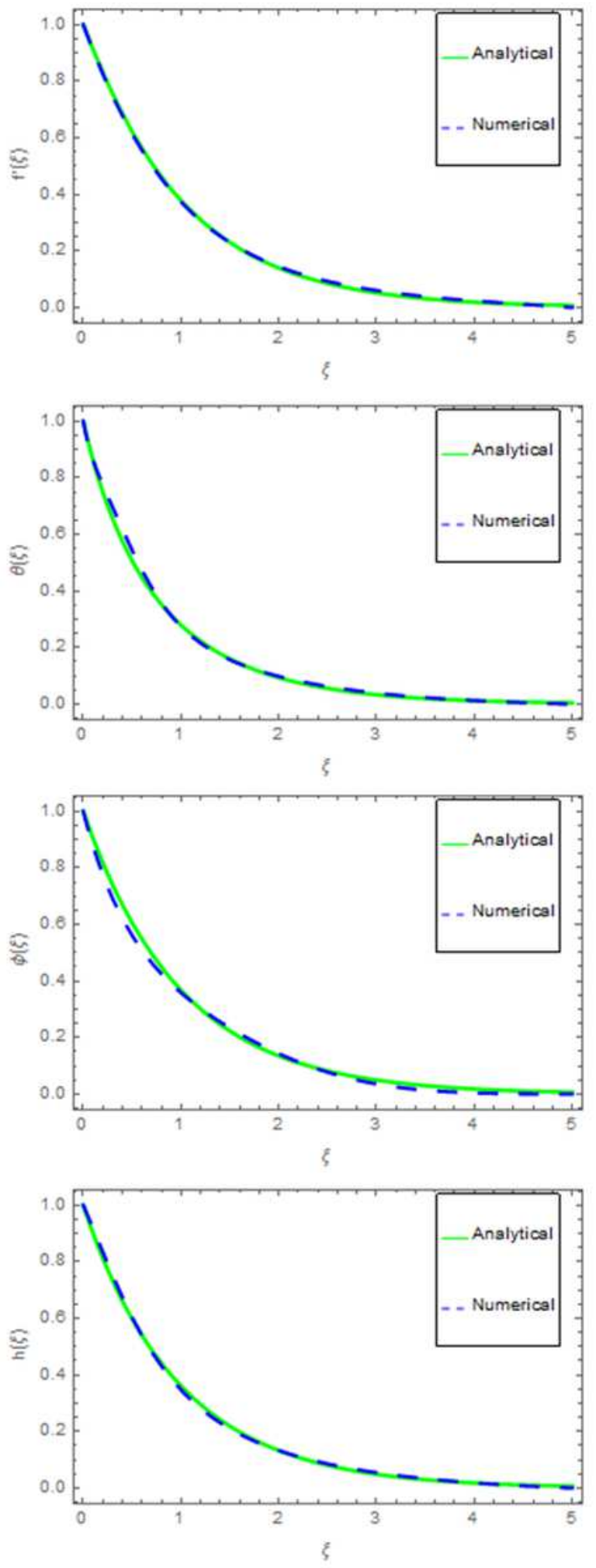

Figure 7

Please see the manuscript PDF file for the full caption 